\title{
LA DELEGACIÓN \\ DE MEDIOS DE COMUNICACIÓN SOCIAL DE LAS DIÓCESIS ESPAÑOLAS
}

\section{INTrODUCCIÓN}

La Iglesia Católica ha mostrado a partir del Segundo Concilio Vaticano una incesante preocupación hacia lo que pudiéramos denominar plausibilidad soctal sobre la naturaleza, el mensaje y la actuación de esta institución". Un interés marcado por la evolución que la comprensión del fenómeno de los medios de comunicación ha sufrido en el seno de la comunidad de creyentes a lo lango de los tiempos. Un proceso de aprehensión caracterizado en nuestros días, según algunos autores, por la ambiguiedad: Se ha dado una profunda ambigiledad en la cultura católica respecto a los mass media. Los caublicos perciten que en cierto sentido estos medios son influyentes, pero al mismo tiempo dejan que se pierdan como insignificantes o bien, más a menudo, como comuptones 2 . Al plantearnos el análisis de los órganos de Comunicación Institucional que la Iglesia constituye para facilitar las relaciones con los instrumentos de comunicación debemos tener en cuenta las actitudes de cautela y reserva que ha practicado a lo largo de su historia. Una situación, en un primer momento, de sospecha en tránsito hacia la aceptación voluntariosa y la comprensión utilitaria. Aceptación siempre encaminada al uso, descle la consciencia de la relevancia de estos instrumentos, y que originará la necesidad de plataformas que faciliten los flujos de información ${ }^{3}$.

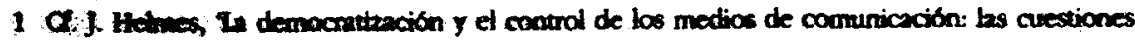

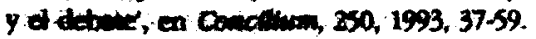

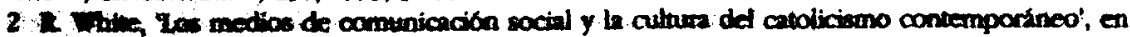

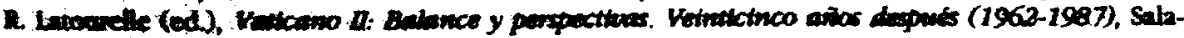
manca 19: 1178.

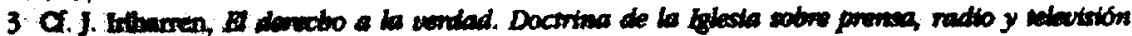
(1831-1968), Midrid 1969, 35; F. Martinez Diez, Teologia de la comunicect6m, Madrid 1994, 48;

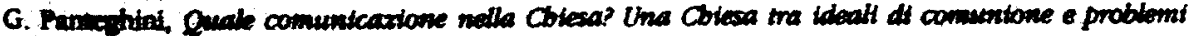
di comanteantow, Bologn 1993, 40. 
Como recoge E. Baragli en su Encbiridion, el pronunciamiento de la Iglesia sobre los medios de difusión ha sido constante a lo largo de los siglos $^{4}$. A partir del nacimiento del periodismo moderno (primera mitad del $\mathrm{xIx}$ ) se intensifica esta relación caracterizada por movimientos de sístole y diástole. Un proceso que nos catapulta hacia la centralidad del Decreto -Inter Mirifica. (4-12-1963), del Concilio Vaticano II ${ }^{5}$ : -Il Concilio ha posto le basi di una nuova teologia e di una nuova prassi della comunicazione soprattutto con l'ecclesiologia della Lumen Gentium e della Gaudium et Spes. Ha prodotto anche un documento specifico sui mezzi di comunicazione sociale, el decreto -Inter Mirifica. del 1963, che ha pèro un lìmite: quello di essere nato prematuramente, mentre la nuova ecclesiologìa istituzionale e alla sua òttica strumentalista. Il documento prende atto dell influsso profondo che i mass media esercitano nella nostra società e stimola i cattolici a utilizzarli in funzione pastorale, ma non sembra ancora sufficientemente avvertito della specifica funzione dei diversi mezzi nel processo comunicativo e nella "mediazione" del messaggio. 6 . A partir de este documento no podemos olvidar dos luminarias: la injustamente olvidada Instrucción Pastoral Communio et Progressio (1971) y la reciente Aetatis Novae (1992).

Este desarrollo de comprensión y entendimiento mutuo, y las consecuencias prácticas de la dimensión pastoral, tiene una vertiente que se refleja en las normas canónicas de la Iglesia. En el marco de la utilización de la prensa como medio de pacificación de los espiritus y de la pugna con las doctrinas adversas y erróneas, encontramos en el CIC 17 las referencias a la censura de los escritos destinados a las publicaciones diarias y periodicas ${ }^{7}$, y la obligación del beneplácito del Ordinario, o la licencia del Superior Mayor en el caso de los religiosos, para escribir o dirigir diarios, hojas y revistas ${ }^{8}$. También nos topamos con la recomendación de no publicar, a no ser por causa justa y razonable, en medios impresos contrarios a la religión 9 .

El vigente Código de Derecho Canónico inicia su Libro III, De la función de enseñar, con una referencia a la utilización de los medios de comu-

4 Cf. E. Baragli, Communicazione, Communione e Cbiesa, Roma 1973.

5 La rocambolesca historia de la elaboración del Decreto, según Joaquin Luis Ortega la cenicienta del Concilio, se puede estudiar en R. de Andres (od), Instrumentos de Comunicacion Sacial, Madrid 1966; J. M. Pascual, Los medios de comunicación social en la doctrina de la lglosia, Madrid 1976; A. Gonzxlez Molina, La Iglesia en la encrucijada de la comunicación social, Madrid 1971; C. M. Stachlin-P. Cebollada, Dacreto sobre los instrumentos de comusticactón soctal. Texto y comentano, Madrid 1965.

6 G. Panteghini, o. c., 40-41.

7 CIC 17, can. 1348.

8 CIC 17, can. 1386.

$9 \mathrm{CIC} 17$, can. 1386. 
nicación social en el anuncio y predicación de la Iglesia ${ }^{10}$. En el Título I, -Del ministerio de la Palabra Divina, el último canon explicita la necesidad de los medios de difusión en la enseñanza de la doctrina cristiana ${ }^{11}$. La predicación de la Palabra de Dios se debe atener a las prescripciones establecidas por el obispo diocesano, según el canon 772 , que, además, especifica que para hablar sobre temas de doctrina cristiana por radio o televisión se han de cumplir las prescripciones establecidas por la Conferencia Episcopal. ${ }^{12}$. Cuando se concreta el aspecto de la formación catequética, en el capítulo II del Título I, otro canon propone la necesidad de utilizar los medios más eficaces ${ }^{13}$. En el Título III, -De la educación católican, se afirma que la enseñanza y educación religiosa católica en escuelas y medios de comunicación depende de la autoridad de la Iglesia ${ }^{14}$.

El Tírulo IV se dedica a los instrumentos de comunicación social, especialmente a los libros. Después de ofrecer un marco general en el canon 822 , se encomienda a los pastores la obligación y el deber de velar para que ni la utilización de los medios de comunicación social, ni los escritos, dañen la fe y las costumbres de los fieles cristianos ${ }^{15}$. El canon 831 recoge, además, la temática del canon 1386 del CIC 1716. Por último, nos encontramos en el capítulo IV del Libro II, De las obligaciones y derechos de los institutos y de sus miembros", con el significado canon 666 sobre la necesaria discreción en el uso de los medios en los casos en que pueda ser nocivo para la vocación o peligroso para la castidad de la persona consagrada.

El Código de Cánones de las Iglesias Orientales dedica dos importantes normas a los instrumentos de comunicación social. Arranca con el canon 651, marco general similar al canon 822 del CIC 83 , en el que resalta la obligación de utilizar los medios adecuados en la misión de anunciar el Evangelio a todo el mundo. Se descubre un mayor aquilatamiento en los conceptos con la referencia a los informadores y su tarea de colaboración en la acción pastoral, de acuerdo con la Aetatis Novae n. 10. Otra novedad importante es la necesidad de formación, con ayuda sobre todo de instituciones de ciencias de la información. ${ }^{17}$.

10 CIC 83, can. 747.

11 CIC 83, can. 761 .

12 CIC 83, can. 772, 2.

$13 \mathrm{CIC} 83$, can. 779 .

14 CIC 83, can. 804.

15 CIC 83, can 823 .

16 E1 Decrea General sobre la presencia de la Iglesia en los medios audiovisuates de comunicación social aparece promulgado en et Boletin Oficial de la Conferencia Eprocopal (BOCEE) 3, 1986, 115-116.

17 CCEO, an. 652. 
En el proceso de conciencia eclesial sobre el fenómeno mediático aparece como órgano fundamental el Consejo Pontificio para las Comunicaciones Sociales. Un mecanismo que en su dilatada vida ha hecho suya la realidad de la aldea global y ha orientado de forma clarividente las iniciativas locales. Una vida que se estructura en dos etapas: -Il Pontificio Consiglio delle Comunicazioni Sociali ha avuto una sua evoluzione, in cui si possono distinguere due tappe principali. La prima si puo definire come quella di una Comissione allo stato di formazione (dal 1948 al 1964); la seconda tappa, invece (dal 1964 fino oggi), come quella del Pontificio Consiglio delle Comunicazioni Sociali sotto l'aspetto attuale. En da sotolineare che nella seconda tappa questo Organismo della Curia Romana si occupa di tutti gli scs nel loro insieme, con i problemi ad essi connessio ${ }^{18}$. De la *Comisión Pontificia para la Cinematografia didáctica y religiosa. (1948) a la constitución del Consejo Pontificio para las Comunicaciones Sociales ${ }^{19}$, en su nueva denominación, han transcurrido unos años clave en el decurso de la aceleración histórica, en los que se manifiesta un notable esfuerzo de la Iglesia por adaptarse a los signos mediáticos de los tiempos.

En nuestro país, los Estatutos de la Conferencia Episcopal Española nos proponen un modelo de organización operativa de institución eclesial, con el fin de promover la vida de la Iglesia, fortalecer su misión evangelizadora y responder de forma más eficaz al mayor bien que la Iglesia debe procurar a los hombres. ${ }^{20}$. A la Comisión Episcopal de Medios de Comunicación se le ofrece el siguiente marco estatutario: según el artículo 29, las Comisiones Episcopales son órganos constituidos por la Conferencia para el estudio y solución de algunos problemas en un campo de la acción pastoral común de la Iglesia en España, en conformidad con las directrices generales aprobadas por la Asamblea Plenaria. ${ }^{21}$. Cada Comisión constará de un presidente y de un número variable de miembros (art. 32), que se reunirán al menos dos veces al año (art. 33). Dentro de las variadas funciones de la Comisión se encuentra la de $22^{\circ}$ Promover a la Comisión Permanente la creación de Secretariados y otros organismos técnicos y, en su caso, dirigir los ya creados; ${ }^{22}$. La Conferencia Episcopal

18 P. Dumiak, II Pontificio Consiglio delle Comundicaziona Sociali. Stonia, smumura e Funzrioni, Roma 1991, 54.

19 Juan Pablo II, Const. Apost. Pastor Bonus, 28 iunii 1988, arts. 169-170.

20 Conferencia Episcopal Española, Estatutos de la Confenencia Eptscopal Españala, en BOCEE, 30, 1991, 43, ar. 1.1.

21 Bbid, ant 29.

22 Ibid, ant. 35. 
Española ha insistido varias veces en la necesidad de establecer similares organismos en las diócesis ${ }^{23}$.

\section{ANÁLISIS DE LA STTUACIÓN ESPAÑOLA}

\subsection{Antecedentes y contexto bistórico}

La preocupación de la Iglesia por establecer puentes con el universo mediático en nuestro siglo, mediante organismos ad casum, parte de la iniciativa de las reuniones de la Junta Nacional de la Prensa Católica (19241956) ${ }^{24}$. En el libro que recoge el Acta de la Junta Nacional de Prensa, del 25 de abril de $1950^{25}$, aparece una breve cita del proyecto de D. Jesús Iribarren sobre una Oficina General de Información y Estadística de la Iglesia. El propio Iribarren nos relata en sus Papeles y Memorias ${ }^{26}$ la trayectoria de constitución de la citada oficina, después de su regreso del Congreso Internacional de Prensa Católica celebrado en Roma el mes de febrero del Año Santo de 1950:

-En abril de 1950 presenté ya un proyecto que podría así resumirse:

$1 .^{\circ}$ Era inviable una nueva o resucitada agencia católica de información general.

23 Conferencia Episcopal Española, 'Los cristianos laicos, Iglesia en el mundo. Líneas de acción y propuestas para promover la corresponsabilidad y participación de los laicos en la vida de la Iglesia y en la sociedad civil', en Boletin Ofictal de la Conferencia Episcopal Española, 33. 1992, 14-41, nn. 108-110.

24 La Junia Nacional de Prensa Católica se cre6 después de la Asamblea de la Buena Prensa celebrada en Toledo en 1924. En las Actas de los Metropolitanos se recoge el momento de su fundacioa en estroninos: -137. La retación hecha por el Emmo. St. Cardenal Presidente acerca del exuraordinario exito de la Asamblea de la Buena Prensa celebrada en Toledo, cuyos resultados prácticos son ta publicación de una revista infantil, ya iniciada; otra gráfica, en preparación; una serie de novelas cortas, a punto de salir a la luz, y un gran rotativo de caracter general, con ediciones especiales para diversas profesiones, ha merecido los más calurosos elogios de los demís metropolitanos. El Emmo. Sr. Presidente se encargará de constituir la Junta Nacional de la Prensa Católica, determinar sus atribuciones y serfabarle medios de subsistencia. Esca Junta dará cuenta de su gestion a los metropolitanos cada vez que estos se retinan. (V. Cárcel Orri led.l, Actas de las Conferencias de Metropoliumas Apaitolex, Madrid 1994, 190). En bs reuniones de noviembre de 1932 y noviembre de 1946 se realian divemas nestructuraciones de la Junta Nacional de la Prensa Catolica, previas a la trascendencal de 1959 , a la que huego nos referiremos.

25 Actus de la funta Nacional de la Prensa Catolica: Acta de la Junta Nacional de Prensa del 25 de abril de 1950, vol orig., sin paginas.

26 J. Istbarren, Pupeles y Memartas. Medio siglo de relaciones Iglesia-Estado en Esparia: 19361986, Madrid 1992. 
2..$^{-}$No era imprescindible en las circunstancias actuales una agencia de noticias religiosas, pues el campo estaba suficientemente cubierto por las otras, con criterios aceptables.

3. Habia un vacio en la Iglesia española, que en algún sentido comprendía la información religiosa; pero que la desbordaba y, saliendo de la competencia de la Junta Nacional de Prensa Católica, afectaba al Episcopado en pleno, cuya anuencia habia que solicitar.

4. Era una Oficina de Información y Estadística de la Iglesia en España, con el siguiente contenido:

b) Hace falta una información intraeclesial que mantenga a los obispos, superiores mayores de órdenes religiosas, Roma, etc., al día en sucesos e ideas que los hombres de gobiemo deben conocer. El Estado tiene, de una forma u otra forma, esos servicios de informacion para autoridades: la Iglesia carece de ellos y los dirigentes se limitan a su periódico.

c) Un complemento útil puede ser la información religiosa al exterior, de cuanto la jerarquía crea necesario divulgar con carácter oficial u oficioso. En este tercio de plan podría actuar la antigua Prensa Asociada si la resucitábamos con un papel restringido e integrado en el nuevo conjunto, más o menos como boletín. La Iglesia española tenía también que preocuparse de informar al extranjero, donde tan desconocida y atacada era. ${ }^{27}$.

En el Acta del 15 de julio de 1951 de la Junta Nacional de la Prensa Católica, punto cuarto, se reseña la necesidad de encontrar medios para iniciar la Oficina de Información (OFies). Las Juntas Nacionales de los días 19 de noviembre y 10 de diciembre de 1951 volvieron a abordar el problema y la necesidad de la creación de esta Oficina. Creada ya la Oficina de Información, una de sus principales tareas fue la confección de un Boletín para los Reverendistmos Prelados, ciclostilado y sin periodicidad fija. De nuevo, D. Jesús Iribarren nos relata la vida de este medio de información y formación:

- En cuanto tuve como instrumento respaldado por ta jerarquia la Oficina de Información y Estadistica, comencé a distribuir, policopiado, un Boletín para los Reverendísimos Prelados, con periodicidad irregular. El primer número lleva fecha de 1 de enero de 1952. Sus destinatarios eran todos y sólo los obispos, más la Nunciatura y Secretarín de Estado.

El Boletin siguió publicándose hasta 1957, pero ese año lo suspendi, abrumado por ta desconfianza de algunos pocos, que suponian que en la 
simple selección de originales se transparentaba alguna hostilidad del director hacia valores estimados intangibles. ${ }^{23}$.

La Conferencia de Arzobispos Metropolitanos creará, en su reunión del 27-29 de noviembre de 1956, la Comisión Episcopal de Cine, Radio y TV:

967. Asimismo se acordó crear una Comisión Episcopal de Cine, Radio y Televisión, presidida por el Emmo. Sr. D. Enrique Delgado Gómez, arzobispo de Pamplona, e integrada por los Excmos. Sres. D. Abilio del Campo, obispo de Calahorra, y D. Antonio Ona, obispo auxiliar de Lugo ${ }^{29}$.

En cada dí́cesis se fueron creando Secretariados de Cine, Radio y Televisión. Sus representantes se reunieron, por primera vez, el 12 de abril de 1958, para, entre otros temas, tratar el reconocimiento legal de la Red de Emisoras que la Iglesia iba formando, su estructuración y ordenamiento, las frecuencias, la técnica y la pastoral ${ }^{30}$. En la Asamblea de Metropolitanos del 2-7 de enero de 1959 se creará otra Comisión Episcopal relacionada con los Medios de Comunicación, en este caso con la Prensa:

.1109. En el tema XV, que decía así: Reorganización de la Junta Nacional de la Prensa Católica, fue ponente el Emmo. Sr. Cardenal Primado, y se adoptó el siguiente acuerdo: "Se crea una Comisión Episcopal de Prensa e Información, de la cual dependerán la Junta Nacional de Prensa Católica, con la Agencia Prensa Asociada, y la Oficina de Información y Estadistica de la Iglesia, todas las cuales cubrirán sus propuestas con la colecta del Dia de la Prensa e Información de la Iglesia". ${ }^{31}$.

Con esta reunión, la Conferencia de Metropolitanos aprueba las bases para la reonganización de la Junta Nacional de Prensa Católica. En este año, clave para el apostolado católico en los medios de comunicación, la Memoria de la Junta Nacional de Prensa Católica dedica su capítulo cuarto a las delegaciones diocesanas ${ }^{32}$. El primer apartado, bajo el título *Reorganiza-

28 J. Iribarren, ibid, 140.

29 v. Carcel Oru (ed), o. c., 528.

30 C. J. Remirez Muneta, El Concilio Vaticano II. La Radio y la Televisión, Madrid 1965, 178.

31 V. Carcel Ont (ed.), o. c., 575. I2s dos Comisiones Episcopales de temática comunicacional se unirín con d acuendo de la Asamblea de Metropolitanos de julio de 1964: 1326. Se acuerca fundir en una sota bes actuales Comisiones Episcopales de Prensa e Información y de Cine, Radio y Television. La nueva Comisión Epixcopal para los Medios de Comunicación Social estara presidida por el Excmo. Sr. D. Pedto Cartero Cundrado, Arzobispo electo de Zaragam, y serán miembros los Excmos. Sres. Otispos de Cabahoma, Lugo, Santander, Malaga y Auxiliar de Sevilla. Ibid., 646.

32 Junta Nacional de Prense Catolica, Actividades en 1959 de la Junta Nacional de Prensa Caublica, cund. multicopindo, pp. 17 y ss. 
ción de los organismos diocesanos", recoge la siguiente declaración de intenciones:

Con el noble afán renovador de los organismos de prensa católica, en las fechas inmediatas al "Día de la Prensa e Información de la Iglesia", por el Sr. obispo presidente se transmitió a los Rvdmos. prelados el deseo que en cada diócesis existiese una Delegación Diocesana de Prensa Católica, que, alentada por la persona que delegase el ordinario de la diócesis, viniese a reemplazar a las sucesivas actividades que, conforme a las diversas etapas de la Junta, han venido desempeñando el cometido.

Dada la trayectoria seguida después de la constitución de las Comisiones Episcopales y de sus Secretariados, se estimó que, asimismo, la Comisión Episcopal de Prensa e Información debería tener, en cada una de las diócesis, un Secretariado promotor de sus actividades.

Correspondiendo a la petición del Sr. obispo presidente, en 31 diócesis quedaron constituidas las Delegaciones Diocesanas de Prensa Católica, cuya labor, en el tiempo transcurrido, ha sido verdaderamente eficaz y ha contribuido, en una parte muy notoria, a realizar los planes de la Junta en cada una de las diócesis, principalmente en la preparación y celebración del "Día de la Prensa e Información de la Iglesia". 33 .

La Junta convocó en los días 25 y 26 de mayo de 1959 la I Reunión Nacional de Delegados diocesanos, que se celebró en los locales del Instituto Central de Cultura Religiosa Superior. Asistieron a la reunión veinticuatro delegados, de las siguientes diócesis: Albacete, Almeria, Astorga, Ávila, Barbastro, Burgos, Coria, Cuenca, Huelva, Ibiza, Jaén, Madrid, Palencia, Pamplona, Salamanca, Segovia, Sigüenza, Teruel, Toledo, Urgel, Valencia, Valladolid, Vitoria y Zamora ${ }^{34}$. Dos conclusiones destacan principalmente: duplicar la colecta del .Día. y promover la constitución de Hermandades diocesanas de periodistas. Con motivo de la reunión se instaló en los locales adyacentes una exposición de Prensa Católica. Entre otras actividades, la -Editorial Católica. recibió a los delegados en su nuevo domicilio. Al final del capítulo IV de la Memoria se especifican las diócesis en las que está

33 Ibid., 17.

34 Los nombres de los detegados eran las siguientes (por el orden citado de las dí́cesis): D. Francisco Fuentes Garcia y D. Vidal Martínez, D. Marino ikvarez Minguea, D. Esteban Carro Celada, D. Tecdoro García Robtedo, D. Benjamín Plaza, D. Bonifacio Zamona Uaabel, D. Antonio Arias Crespo, D. Martin Garcts Masegos, D. Ildefoaso Torres Candona, D. Andrts Molina Prieto, D. Luis Marcos, D. Zacarias Gama, D. Joec Maria Diaz Mozaz, D. Lamberto de Echevama, D. Lucas Garcia Borreguero, D. Saturnino Marfil Gallego, D. Bduardo Perez Baseler, D. Francieco Vidal Soler, D. Joaquíb Mur, D. Juan Comes Domenech, D. Martía Hermandez Gonzalez, D. Santiogo lbaz y D. Nicoliss Rodríguez Femández. 
constituida la Delegación de Prensa Católica: Albacete, Almería, Astorga, Ávila, Bilbao, Burgos, Coria, Cuenca, Granada, Huelva, Huesca, Ibiza, Jaén, Madrid, Mondoñedo, Orihuela, Osma, Oviedo, Palencia, Pamplona, Salamanca, Segovia, Sevilla, Sigüenza, Teruel, Toledo, Valencia, Valladolid, Vich, Vitoria y Zamora. Son 31 Delegaciones de las que tiene constancia la Junta. Aún faltan por erigirse estos organismos en Badajoz, Barbastro, Barcelona, Cádiz-Ceuta, Calahorra, Canarias, Cartagena-Murcia, Ciudad Real, Ciudad Rodrigo, Córdoba, Gerona, Guadix, Jaca, León, Lérida, Lugo, Málaga, Mallorca, Menorca, Orense, Plasencia, Santander, Santiago, San Sebastián, Segorbe, Solsona, Tarazona, Tarragona, Tenerife, Tortosa, Tudela, Tuy, Urgel y Zaragoza.

Como hemos podido observar, 1959 marca una nueva etapa en la historia de la Comunicación Institucional de la Iglesia. Una Junta Nacional de Prensa renovada, consciente de la necesidad de estos organismos llamados Delegaciones Diocesanas de Prensa Católica, antecedentes próximos de nuestras Delegaciones de Medios de Comunicación Social. Se resalta el carácter central de la Jornada, o Día, de la Prensa e Información en la Iglesia, así como el trabajo con los profesionales. No quedaba lejana la insistencia de la Iglesia en nuestro país por la responsabilidad del periodista y su función de mediador social.

\subsection{La Comisión Episcopal de Medios de Comunicación Social de la Conferencia Episcopal Española}

La Comisión Episcopal de Medios de Comunicación de la Conferencia Episcopal Española nació como tal en la Asamblea Plenaria de 26 de febrero-4 marzo de 1966, momento en que se constituyó la propia Conferencia ${ }^{35}$. Su fruto más joven y relevante fue el Boletín del Secretariado de la Comisión Episcopal de Medios de Comunicación, publicado por primera vez con fecha de 8 de febrero de 1969. Supone el principal esfuerzo de cohesión, en esa época, en la labor de la Iglesia, tanto de cara a las diócesis como de definición de su tarea.

Ya en su primer número se reseña la reunión de delegados diocesanos celebrada en Murcia el 14 de enero de 1969, con la participación de los representantes de Murcia, Madrid y Gerona. En la página 4 se recoge el siguiente manifiesto:

35 Cr. Oficina de Sociología y Estadistica de la Iglesia, Guia de Medios de Comunicación Social de la lglesta en Espasia, Madrid 1976; Oficina de Estadistica y Sociología de la Iglesia, Medios de Comunicactón Social. Liesta Caroitica en España. Guía 1991, Madrid 1991. 
UNA COOPERACIÓN MUY URGENTE:

De los cambios de impresión que ya hemos tenido sobre la "figura" del Delegado Diocesano, delegaciones, labor, etc., va sin duda perfilándose algo que podriamos llamar el Estatuto del Delegado Diocesano de Medios de Comunicación Social. Incluso algo escrito se está preparando. Más que en el papel lo importante es que en su actuación -en la diócesis y en el plano nacionat- se vaya configurando la Delegación Diocesana y el delegado.

Uno de los puntos que habrá que tratar es el del delegado diocesano como informador de los hechos religiosos en su diócesis, para un conocimiento de toda la comunidad española. De momento y URGENTEMRNTE el Secretariado ruega a los delegados diocesanos la siguiente colaboración:

1. Que interesen a su propio prelado, obispos auxiliares o vicarios episcopales en que aquellos documentos que puedan tener interés "nacional" (y son casi todos, dada la importancia actual de la noticia religiosa), nos hagan legar -o directamente o mejor por medio del delegado- informa. ción lo más completa posible, y 10 ANTES POSBBre, inchuso con antictpación, para que oportunamente se pueda preparar y dar la información adecuada. Nota importante--No se trata de una mera propaganda o de copiar fragmentos de las cartas pastorales de los prelados, sino de recoger de las decisiones y doctrina de los obispos españoles aquello que tenga interés informativo y señale alguna actividad constructiva de la Iglesia española. ${ }^{36}$.

Como se puede ver, en la primera reunión aparece la cuestión de la definición de la figura y misión de la Delegación y del delegado. Nos es dificil conocer cuáles son los modelos en los que se fijan y cuáles sus referencias en instituciones del mundo civil. Otro aspecto es la configuración y el carácter jurídico de estos entes, que se reflejara en los Estatutos aludidos. No debemos olvidar la estrecha relación de la misión de estos organismos con la Jornada Mundial de las Comunicaciones Sociales. Motivo que aparece en el Boletin número 2, del 14 de marzo de 1969:

-ESQUEMA DE ACCIONES DE UN SECRETARLADO DIOCESANO:

1. Carta pastoral del Sr. obispo sobre la Jomada

Mons. Cantero les escribe previamente y les envia un dossier doctrinal sobre la Jornada y su lema. Este material lo reciben también, mas amplio, los delegados.

Labor del delegado: insistir y difundir con tiempo.

36 Secretariado Nacional de la Comision Episcopal de Medios de Commicación, Bolman dal Secretariado, 1, 1969, 4. 
2. Carta a los sacerdotes (especialmente a los párrocos) sobre la Jornada firmada por el Sr. obispo o el vicario general o pastoral, o por el delegado. Rogándoles cooperación y avisándoles del envio de material.

3. Envio a los sacerdotes (mejor unos días después de la carta) de material (folleto sobre la Jornada, esquema de homilia, preces de los fieles), que facilitará el Secretariado nacional.

4. Interesar al Consejo del presbiterio, al Consejo de pastoral, etc., de la Jornada, por carta o en alguna reunión que celebren.

5. Difusión en los colegios dependientes del obispado, parroquias, etc., del texto de una lección sobre medios de comunicación.

6. Recabar colaboración de las asociaciones y movimientos apostólicos familiares, recordando el lema de las Jomadas de este año.

7. Mantener contacto con los cine-forum y tele-clubs de las diócesis, interesándoles en la programación de temas referentes a las comunicaciones sociales.

8. Enviar a la Agencia Prensa Asociada información sobre las diversas iniciativas diocesanas, para su publicación.

9. Contacto personal con los directores de prensa local y radio locales (con una copa o comida). Agradecerles la colaboración que prestan; anunciarles la Jornada y objetivos concretos; darles material (preparado por la Delegación Diocesana o el Secretariado Nacional).

10. Reunión del Sr. obispo con los directores de Prensa y Radio (para agradecerles...).

11. Editar con tiempo en el Boletín Oficial del Obispado y en la Hoja Diocesana material sobre la Jomada. En la Hoja Diocesana hacerlo en el número del 11 de mayo, principalmente. Si hay emisora COPE, incorporar al director en el montaje y preparación de la jornada.

12. Próximo el dia mundial, preparar algún acto de cierto relieve: conferencia (para una minoría interesada). Sería útil recalcar la cooperación de la Asociación de la Prensa local. Sesión de cine (para sacerdotes, religiosos, etc.): una película importante, con una introducción de cinco minutos sobre la película y la jomada.

13. Interesar personalmente a quienes corresponda para la inserción de articulos, noticias, etc., sobre la Jomada en prensa y radio locales. Publicacion del cartel.

14. Misa de los Medios de Comunicación Social (habrá que garantizar un minimo de asistencia), homilia especial y preces hechas por los representantes de los medios ${ }^{37}$. 
Estas indicaciones se repetirán en el Boletín en sucesivos años. Como se puede observar, se cargan las tintas en la preparación de la Jornada. Desde la concienciación del obispo y los responsables eclesiásticos hasta la de los directores de medios pasando por los grandes actos. Normas muy prácticas, garantizar un minimo de asistencia a la misa..., para llevar a buen término la estrella de las actividades de las Delegaciones. En este escrito se conjugan los dos campos de actuación que a partir de ahora empezarán a delimitarse: actividades ad intra y ad extra.

En el Boletin del 18 de febrero de 1970 se habla de la reunión de delegados, en la que se ha nombrado una comisión para el secretariado, sin más especificaciones ${ }^{38}$.

La combinación de indicaciones teóricas y prácticas por parte del Boletin va configurando el camino hacia la clarificación de lo que puede ser una Delegación de Medios de Comunicación Social. Un servicio, dentro de la Curia Diocesana, que se ocupa principalmente de los ámbitos de las relaciones con los medios, de las relaciones públicas y de la edición del Boletin eclesiástico y las incipientes Hojas Diocesanas. Todavía faltarán muchos años para abordar el problema de la formación de la imagen pública de los líderes, obispos en este caso, y de la institución. En este iter aparece como fundamental un documento publicado por el Boletin del Secretariado en junio de $1970^{39}$, de la Secretaría General de la UCIP (Unión Católica Internacional de la Prensa), sobre las relaciones entre las organizaciones de periódicos y periodistas católicos y los organismos episcopales de medios de comunicación, bajo el título PERIODISTAS CATÓLICOS Y JERARQUIA ECLESLAL. No aparece la fecha en que la UCIP ha redactado este documento. En la introducción se aclara que do facilitamos a los delegados diocesanos por estimar que posee un doble interés: informativo, en primer lugar, y orientador para las Oficinas diocesanas de Información y Comunicación Social.

Uno de los problemas que nos empezamos a encontrar es el de la denominación de este organismo. Problema aún no resuelto, ni desde la legislación, ni desde la práctica de la pastoral de los medios ${ }^{40}$.

PERIODISTAS CATÓLICOS Y JERARQUí ECLESLAL consta, según el esquema previo, de cinco puntos: La jerarquía organiza sus -Relaciones Públicas, las publicaciones de carácter apostólico, Prensa de información de la Iglesia, Prensa de los católicos y católicos en la prensa, y Apoyar a las oficinas de MCS. El documento tiene una parte clara de concienciación de lo que es la

38 Boletin del Secretaniado, 6, 1970, 5.

39 Boletin del Secretarlado, 13, 1970, 1 y ss.

40 C. AM.VV., La Curia Episcopal. Reforma y actualizacion, Satamonca 1979. 
identidad del medio y del periodista católico y de lo que supone el apostolado católico. En el principio del escrito se define y aplica el principio de subsidiariedad como base de actuación de las iniciativas que surgen del Pueblo de Dios, para después referirse a la atención pastoral que sobre estas iniciativas ejerce la jerarquía. La pregunta clave aparece en las primeras líneas: Si las oficinas nacionales que la jerarquía eclesiástica desea organizar en todos los países a las órdenes directas de una Comisión Episcopal o de un obispo delegado llegan en efecto a constituirse como organismos de acción pastoral, ipodrá decirse que la UCIP tiene por función ayudar a las oficinas nacionales a cumplir la misión de éstas y estudiar los aspectos mundiales del apostolado por medio de la prensa?

$O$, por el contrario, la prensa (considerada en general) ¿está entre las actividades profesionales nacidas del "pueblo", orientadas, pero no organizadas o dirigidas, o utilizadas como instrumento propio por la jerarquía? ¿Cuál es el grado de autonomia organizativa que deben disponer los periódicos, los periodistas católicos, las escuelas de periodismo, las agencias católicas de prensa, sus asociaciones nacionales e internacionales? ¿Cuál es su enlace con los organismos pastorales?. ${ }^{41}$. Estas cuestiones aparecen como preámbulo a la parte que a nosotros más nos interesa. Son significativas del contexto en el que se está desarrollando la creación de los organismos nacionales y diocesanos de información. Organismos que se justifican en el apartado I:

\section{LA JERARQUUA ORGANIzA SUS "RELACIONES PÚbLICAS"}

Toda organización modernamente concebida (industrial, comercial, religiosa, politica...), en cuanto sobrepasa cierto tamaño mínimo, necesita montar su propia información sobre la base y la cumbre: de lo contrario el mando queda aisiado (de los obreros, de los clientes, de los fieles, de los ciudadanos). De la buena o mala organización de la información interior depende en mucha medida el acierto de las órdenes de los superiores, su aceptación sincera por quienes han de cumplirlas, el entusiasmo en la acción común o bien conflictos innumerables y, en definitiva, la ineficacia. La información interior, en las dos direcciones, es el primero y más elemental capitulo de lo que hoy se conoce como "relaciones humanas" de una empresa.

A las "relaciones humanas" se añaden las "relaciones públicas". Las organizaciones modernas saben que hay que exponer los propios puntos de vista, prevenir las reacciones contrarias de la opinión pública, neutralizar las campañas adversas cuando éstas se han producido, y todo ello sin faltar 
a la verdad ni presionar injustamente sobre las ideas o los sentimientos de los otros, pero tratando de presentar una imagen favorable que, en definitiva, corresponda a la realidad. También las "relaciones públicas" bien llevadas son hoy condición sine qua non de la eficacia de la vida social. Todos los estamentos eclesiásticos van cayendo en la cuenta de que, como cualquier marca industrial o cualquier oficina del Estado, necesitan poner en marcha servicios de documentación (biblioteca, fototeca, estadisticas) al servicio de todo el que solicite datos; de que deben, cuando sea preciso, celebrar una rueda de prensa o dar a conocer un comunicado; de que tienen la imperiosa necesidad de mantener el contacto con los profesionales de la información. ${ }^{42}$.

A partir de aquí el documento se dedica a reflexionar sobre el papel de la UCIP en este sistema de contribución para el desarrollo de una comunicación interna fluida, tanto en los países como en las regiones, y en la formación de esa imagen pública de la Iglesia. Aconseja esta organización, en el marco interior, que da colaboración de la prensa y de los periodistas católicos a las relaciones públicas de la Iglesia jerárquica podría ser muy intensa. Un resultado indirecto, pero importante, de esa colaboración podría ser descargar a las oficinas de información (o de relaciones públicas) de la Iglesia de mucho peso muerto (burocracia, personal, presupuesto...); ya que no se verian obligados a hacer directamente todas aquellas cosas que la prensa y los periodistas católicos harían gustosamente en su lugar. ${ }^{43}$. La contribución de esta organización, y de los periodistas católicos, apunta a la responsabilidad en las tareas, haciendo una acusación velada de excesiva burocratización de las delegaciones. Después, el documento explicita una de las funciones de las delegaciones cuando se refiere a las publicaciones de carácter apostólico. .En el primero de los casos, a la jerarquía le corresponde de manera estricta la dirección, organización, coordinación de "su" prensa. Esta tarea de impulso y coordinación permanente puede ser delegada en una Comisión ad boc. Y, en efecto, a las comisiones episcopales de MCS en cada nación y diócesis les está encomendada tal función: "4t. Al final, y refiriéndose a la prensa que denomina de información de la Iglesia. preocupados por el problema de fondo de la autonomía frente al status jerárquico, el documento hace la siguiente advertencia: Hay el peligro de que organice "dentro de sí", encerrándose en lugar de abrirse al exterior. Examinando de cerca algunas oficinas nacionales de MCS se observa una composición exclusivamente o al menos preponderantemente eclesiástica: sacer- 
dotes, religiosos, religiosas, miembros de asociaciones apostólicas. Todo el mundo auténticamente profesional (prensa, radio, televisión, oficinas de información, relaciones públicas, escuelas, agencias) sigue su marcha paralela, al margen de la jerarquia. 45 .

El Boletin del Secretariado continúa en años sucesivos en el servicio de luminaria en las actividades que se pueden organizar, a la vez que recoge noticias de las diócesis a modo de caja común de ideas y actividades. De entre las propuestas podemos destacar el esquema para un posible documento pastoral sobre las Jornadas de Medios de Comunicación Social para los obispos *; modelo de plan para las actividades que un sacerdote, una comunidad de religiosos/as pueden hacer con motivo de la celebración de la Jornada ${ }^{47}$; modelo de carta a los curas para hablar de la Jornada o guión radiofónico de las cuñas para la Jomada de Medios de Comunicación Social ${ }^{48}$.

De entre las páginas del órgano de comunicación-comunión del Secretariado merecen destacar en este período dos informaciones. La primera hace referencia a la publicación, en el número 28 , de una información de Albacete, con un breve esquema de la finalidad de la Delegación para ese curso, que puede servirnos como ejemplo de lo que habitualmente se está haciendo y se difunde en el Boletin:

aINALIDAD DE ESTA DELEGACIÓN:

- Información y coordinación de hechos de la vida diocesana que repercutan en los fieles.

SE CONCRETÓ:

1. Mandar, por medio de esta oficina, a los Medios de Comunicación locales las Pastorales que el Sr. obispo hace con motivo de las diversas celebraciones.

2. Convocar una rueda de prensa con el Sr. obispo, en torno al Año Santo, que se está celebrando en la diócesis.

3. Que el delegado diocesano haga un boceto de Reglamento de esta Delegación y mandarto a cada miembro antes de la próxima reunión. ${ }^{49}$.

La segunda referencia viene determinada por la reorganización de las Comisiones Episcopales en la Conferencia Episcopal Española, con el siguiente programa de la de Medios de Comunicación:

45 Ibid., 8.

46 Boletin del Socretaniado, 18, 1972, 72-73.

47 Boletin del Secriataila, 31, 1974, 7475.

48 Boletin del Secruariado, 40,1975, 25 y ss.

49 Bolotin dal Secretariado, 28, 1974, 12. 
- OBJETTVOS CONCRETOS DE LA COMISIÓN EPISCOPAL DE MEDIOS DE COMUNICACTón SOCIAL:

Con motivo del Proyecto de reorganización de las Comisiones Episcopales, el Secretariado de la Comisión de MCS resumió los objetivos concretos de dicha Comisión de la siguiente manera:

1. Representación oficial de la Iglesia en el ámbito social de los MCS:

- Relaciones con los organismos correspondientes de la administración pública.

- Representación de la Conferencia ante Radio Popular de Madrid y la COPE.

- Relaciones con los medios - privados y estatales- de comunicación social.

- Representación oficial de los MCS dentro de los organismos y asociaciones eclesiales.

2. Información oficial de la Iglesia, tanto de ésta hacia la sociedad, como dentro de la misma Iglesia.

Son objetivos de esta información:

- Notificar las decisiones de la Conferencia Episcopal.

- Difundir los documentos emanados de la Santa Sede y organismos eclesiásticos (funciones que ejercita tanto por medio de su Secretartado como por medio de su Agencia y su emisora central).

- Comunicar las diversas actividades o acciones de distintos sectores de la vida de la Iglesia (función, principalmente, de su agencia).

3. Formación pastoral en materia de MCS, función que realiza específicamente con la Jornada Mundial de las Comunicaciones Sociales, según ordenó el Concilio.

- Formación para profesionales de MCS (Escuela de Periodismo).

- Formación para religiosos (CIFMER).

- Formación de la opinión pública y de los fieles (Jornada Mundia).

- Servicios y medios especiales para la formación son su red de emisoras de Radio Popular, las Delegaciones de su secretariado, Publicaciones del mismo, etc.

4. Difusión del mensaje evangélico a traves de los MCS:

- La predicación apostólica, en el mundo actual, como recuenda el Concilio y la encuesta del Sínodo 1974, se entiende en su mayor parte a través de los medios habituales que utiliza la sociedad: MCS.

- Es objetivo de la Comisión cuidar que el mensaje se comunique a escala supradiocesana, especialmente en Radio y TV (a este objetivo alude la proposición $5 .^{2}$ de la XVIII Asamblea Plenaria del Episcopado). 
- Cuidar que el mensaje no sea desvirtuado a escala supradiocesana (asesores religiosos de programación). ${ }^{\text {so. }}$.

Nos introducimos en una nueva etapa que tuvo su primer fruto en un nuevo Boletin del Secretariado, que salió con su número 0 en octubre de 1975, después de la reunión con los delegados diocesanos celebrada del 29 de sepciembre al 1 de octubre de 1974, y de la que el P. Rafael de Andrés, SJ, por entonces director del Secretariado Nacional de MCS, da la siguiente cuenta:

1) Dada la acogida unánime a la idea de un Boletín de MCS, manifestada por todos los que asististeis a la última Reunión, celebrada del 29 de septiembre al 1 de octubre en este Secretariado, ahí va el núm. 0 . Como os indiqué de palabra y por escrito, la finalidad del Boletín es la de poner en conocimiento de los delegados diocesanos y otros organismos, y personas a quienes pueda interesar, una información de todo lo relativo a MCS que se produce en el mundo, en sus aspectos humanos, éticos, profesionales, técrnicos y religiosos.

II) Este número 0, sin embargo, estará dedicado a resumir la última reunión de delegados y a preparar la próxima, que todos nos comprometimos a celebrar hacia finales de año. Este resumen, podrá servir de recordatorio a los asistentes y de información a los que no asistieron.

IV) Por voluntad expresa de todos los delegados asistentes, se fijó la próxima reunión nacional para fin de este trimestre, por urgencia de algunos de los temas seleccionados por ellos mismos: 1) Asamblea Episcopal sobre MCS para 1976; 2) Preparación de la X Jornada Mundial de MCS...

vil) Acerca del Organigrama de las Delegaciones Diocesanas de MCS fue muy interesante el informe oral que disteis los asistentes a la reunión. Pero, como todos consentimos entonces, es muy conveniente tener por escrito las de todas las difcesis para muruo conocimiento de lo común y variante, que puede enriquecemos a todos. El esquema podría ser: 1) NOMBRE / 2) PERSONAS (sacerdotes, religiosos, seglares) / 3) DEPARTAMENTOS / 4) ACTMIDADES " 1 .

A la citada Reunión de Delegados Diocesanos ${ }^{52}$ asistieron los representantes de las siguientes diocesis: Albacete, Almería, Astorga, Barbastro,

50 Baletin del Secreariado, 36, 1974, 493-494.

51 Boletin dal Secretantado, epoca II, 0, 1975, 1-3.

52 Presidida por Mons. Jost Maria Cirarda, obispo de Cordoba y presidente de la Comisión de MCS; D. Manon Cunill, delegado general de dicha Comision, y el P. Rafzel de Andres, SI, director 
Barcelona, Bilbao, Ciudad Real, Ciudad Rodrigo, Códoba, Granada, Logroño, Madrid, Málaga, Mallorca, Oviedo, Pamplona, Santiago de Compostela, Segorbe-Castellón, Seo de Urgel, Santander, Sevilla, Tarazona, Toledo, Tortosa, Valencia, Valladolid, Vich y Zaragoza (28). Excusaron su asistencia los delegados de Badajoz, Burgos, Coria-Cáceres, Huelva, Jaén, Solsona, TuyVigo y Vitoria (8). No contestaron: Cádiz, Canarias, Cartagena-Murcia, Cuenca, Huesca, Ibiza, Jaca, León, Lérida, Lugo, Menorca, Mondoñedo-El Ferrol, Orihuela-Alicante, Salamanca, San Sebastián, Segovia, Tarragona, Tenerife, Teruel y Zamora (20). Según el Boletín no tenian delegados: Ávila, Gerona, Guadix, Orense, Osma-Soria, Palencia, Plasencia y Siguienza (8).

En el orden del día de la asamblea la primera comunicación corrió a cargo del obispo presidente. En un balance de la Comisión Episcopal, declaró que rrespecto al pasado no puede afirmarse que la Comisión Episcopal no haya hecho nada; ha sido una labor callada y delicada que no podia trascender a la calle. Radio Popular de Madrid ha absorbido a la Comisión hasta el punto de impedir otras acciones. Las relaciones con la Administración del Estado, por cuestiones de emisoras y más aún de revistas, han sido múltiples y delicadas. Tanto el obispo presidente como el delegado general han tenido que renovar sus planteamientos a cuatro ministros de Información y Turismo. Por otra parte, el Secretariado Nacional ha padecido una crisis interna, agravada porque la Comisión Pontificia de MCS de la Santa Sede se llevó al Vaticano al director anterior. ${ }^{53}$. De entre los objetivos que Mons. Cirarda marca para esta nueva etapa se encuentra el de potenciar los Secretariados Diocesanos, urgiendo a los Sres. obispos a que atiendan esta tarea en sus diócesis: creando secretariados donde no los hay, enriqueciendo los ya existentes, etc. ${ }^{54}$. Se hace mucho hincapié en la potenciación de la COPE para que llegue a ser una cadena auténtica de emisoras, no sólo para que subsista. 55 . Otro de los puntos es la preparación de una Asam-

del Secretariado de MCS. Según testimonio oral, al hacer la reforma de las comisiones se mantuvo a D. Ramón Cunill al frente de un cargo honofifico como delegado general, y se creb el nuevo equipo del Secretariado.

53 Boletin del Secretariado, Epoca II, 0, 1975, 3 y 4.

54 Ibid., 4.

55 Interesante el informe que presento el director general de radio Popular, S. A., D. Valentín Sebastirn. Y que se recoge en el Boletin número 0 de la siguiente forma: ta cadena de emisoras de la Iglesia consta de 45, y son concesión del Estado a los señores obispos. Once de ellas dependen de los jesuitas, seis de las dominicos y las demis de los propios obispos o entidades comisionadas. Radio Popular, S. A., en su versión comencial, tiene una misión puramente publictaria; es una persona civil, con función técnica y representativa. Cada una de las emisoras son autonomas y de dificil coordinación, lo que ocasiona problemas estructurales muy serios. El momento presente es esperanzador, por lo que se ha conseguido progresivamente, pero las dificultades de todo tipo, incluso ante ba Administración, son preocupantes. Importa que la COPE exista. Es pricticamente la única cadena independiente. A pesar de las limiectones, es importante sabes que las emisoras de in lgteria transmi. 
blea Plenaria de los obispos sobre Medios de Comunicación, que sirva para concienciar a los prelados de la importancia de estos instrumentos.

Un nuevo impulso se estaba intentando en relación con el binomio Secretariado de la Comisión Episcopal de Medios y Delegaciones Diocesanas. La COPE ya ha adquirido, según se colige, cierta autonomía. Quizá se planteó una nueva hora de actuación, con nuevos métodos y otras formas, ante un contexto social-cultural y politico diferente. Sobre las relaciones con la llamada Administración y los ministros de Información y Turismo no debemos olvidar la comisión formada por el Gobierno y la Conferencia Episcopal que adoptó el Decreto 2246/1966, de 23 de julio, por el que se establecía el Estatuto de las publicaciones de la Iglesia. Se diferenciaban así diversos tipos de publicaciones:

- Los Boletines o publicaciones oficiales de la Conferencia Episcopal, los boletines de las distintas diócesis, así como reproducciones de textos que puedan hacer éstas y que puedan considerarse separatas, Boletines Oficiales de Órdenes, Congregaciones e Institutos religiosos. Todas estas publicaciones tienen como característica que la edición, impresión y distribución quedan excluidas de los preceptos de la Ley 14/66, de Prensa e Imprenta, quedando sometidas a la autoridad eclesiástica.

- Las publicaciones periódicas de información general editadas por instituciones eclesiásticas que estarán sometidas en todo a la ley de Prensa.

- Las publicaciones de instituciones eclesiásticas sometidas a la autoridad episcopal previo informe o propuesta de la Comisión de MCS de la Conferencia Episcopal al Ministerio de la Presidencia están sometidas a las normas de la ley de Prensa, pero podrán ser eximidas de la exigencia del artículo 14 del director periodista, y también de la obligación de las inserciones de notas de la Administración pública a que se refiere el artículo 6 de dicha ley, así como de las disposiciones que regulaban la inscripción en el registro de empresas periodísticas.

Sobre las Delegaciones Diocesanas en relación con la radiodifusión conviene recordar el Decreto de 23 de diciembre de 1964, en el que se concede a la Comisión Episcopal una emisora en Madrid de veinte kilovatios, y una más por provincia, de dos kilovatios ${ }^{56}$.

ten un espiritu cristiano en su concepción programática general. Sin embargo, el problema estructural de b COPE - absotuta autonomia de cads emisora- puede dificultar el porvenir: o nos unimos estrechamente o nos espera un futuro problemático.

56 L de Echevarta, Posición fundica de la Iglesia en España ante los Medios de Comunicación Social', en Construción y relaciones Iglesia-Estado en la actualidad, Salamanca 1978, 162, nota 25 
Algunos datos que debemos tener en cuenta en este periodo son:

- Como consecuencia del Concilio pastoral de Galicia comenzó a funcionar la Oficina de Información de la Iglesia en Galicia (ODIGA).

- El Boletin del Secretariado urge a las diócesis para que les envien los informes de las actividades para darlas a conocer en el Boletin 57 .

\subsection{La XXIX Asamblea Plenaria \\ de la Conferencia Episcopal Española de junio de 1978}

El Boletin del Secretariado, a partir de este momento, se dedicará a preparar la Asamblea Plenaria de los Obispos sobre MCS, que se celebrará, después de un tortuoso camino de aplazamientos, en junio de 1978, haciendo el número XXIX. Allí nació el Instituto INTER, de exigua vida, y los encuentros de informadores religiosos, antecedente de las recientes Jornadas de Comunicadores Cristianos. Una de las conclusiones de la citada Asamblea Episcopal, la primera parte del apartado cuatro, recomienda a los obispos la creación o renovación de las Delegaciones Diocesanas ${ }^{58}$. Recomendación que fue glosada por Salvador Petit, en el primer encuentro de informadores religiosos, celebrado en la Fundación Pablo VI en Madrid, del 1-4 de mayo de 1980, con su ponencia sobre ta díbcesis como fuente informativa*. El entonces director de la Oficina diocesana de Información de Sevilla emitió un duro juicio sobre la delegaciones de medios españolas:

¿¿Y quién, en la práctica, se encargara de convertir la vida de la Iglesia en información de actualidad? Por su propin naturaleza, en el mundo moderno este trabajo es un trabajo especinlizado y estŕ confiado a la que suele llamarse una oficina de prensa. A esto apunta pragmáticamente, según sospecho, uno de los frutos que se pretende lograr con estas jornadas: que en la Iglesia española se creen o se potencien por todas partes oficinas de prensa que se encarguen de hacer posible esta dimensión nueva que la vida y la actividad pastoral de la Iglesia ha adquirido en la era de las comunicaciones sociales. Quisiera dejar bien clara mi opinión de que en España no han logrado muchas diocesis disponer de una oficina de prensa por un error de método, queriendo empezar la casa por el tejado; o por un espejismo estéril. hacer una estructura antes que una función $\%$.

57 Boletin del Secretariado, tpaca 11, 26, 1976, 60.

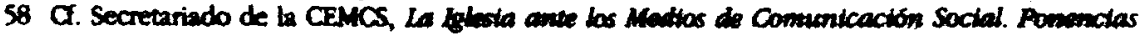
de la XXXXX Asambiea tscopal expariola, Madrid 1978.

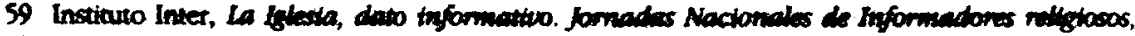
Madrid 1960,154 y $s$. 
En el apartado final de la ponencia especifica los objetivos y las tareas que, a su entender, debe llevar a cabo una oficina de prensa (aquí se incide en el aspecto de las relaciones con los medios al utilizar la terminología de Oficina de prensa). Su proyecto se basa en la Communio et Progressio, glosando los números 138 a 141.

A partir de estas jornadas, que, repetimos, marcaron un nuevo hito, se intensifica la acción del Secretariado de la Comisión Episcopal de Medios de Comunicación para la creación o consolidación de las Delegaciones. Se solidifican ciertos proyectos; las ideas empiezan a aparecer con más nitidez. Resumimos algunos de los avances que marcaron una nueva trayectoria:

- Publicación en el Boletín de octubre de 1978 de un anexo con el título Organizaciōn de una Delegación Diocesana de Medios de Comunicación Social, con los capitulos: -Finalidad de este organismo-, -Servicios técnicos- y servicios pastorales. Además se incluye un proyecto de estatutos, con los apartados: Concepto y finalidad, Servicio técnico de la Oficina diocesana de MCS, Pastoral de los medios de comunicación, Personal de la delegación diocesana y de la oficina técnica e Instalaciones, servicios y dotación de la delegación de medios ${ }^{60}$.

- Creación por la Provincia Eclesiástica Tarraconense del Secretariado Interdiocesano de Medios de Comunicación (SIMCOS), 29 mayo $1979{ }^{61}$. Según los Estatutos, el SIMCOS es el órgano creado por la CET (Conferencia Episcopal Tarraconense) para procurar la recta formación de la conciencia de los fieles en el uso de los MCS y fomentar y orientar lo que los católicos hagan es este campo. Además acoordinará y potenciará las Delegaciones diocesanas de MCS y establecerá conexión y colaborará a tenor de sus posibilidades con la Comisión Episcopal de MCS. ${ }^{62}$. En el apartado de las funciones nos encontramos con las siguientes propuestas:

-a) El estudio atento de todo el campo de la comunicación social.

b) La ordenación de estos medios dentro de toda la acción pastoral.

c) Promover el desarrollo y la colaboración de todas aquellas asociaciones y personas que realicen su apostolado con los MCS.

d) Orientar la adecuada preparación de emisiones y actividades de contenido religioso.

e) Comunicar oficialmente las noticias de la CET y reunir los documentos de la Iglesia para la dífusión pública, de manera que, comentados, los haga más comprensibles a los receptores de los MCS. 
$f$ Asegurar un cambio de noticias e informaciones que presenten la verdadera imagen de la Iglesia y que recoja las reacciones y los anhelos del pueblo, con el fin de informar a las propias autoridades eclesiásticas.

g) Para tener un diálogo auténtico dentro y fuera de la Iglesia, facilitará los comentarios públicos y "oficiales" que oportunamente deberán llegar a los receptores de los MCS de manera segura, adecuada y con los medios oportunos (comunicados, telex, fotografias), dando claridad a los hechos, en la medida que lo pidan los acontecimientos y tas noticias.

b) Colaborará con la CEMCS para facilitar la producción y distribución de films, transmisiones de Radio y de Televisión, de material audiovisual y de publicaciones útiles para el desarrollo de la comunicación humana y de la propia del Pueblo de Dios 63.

- Un modelo válido fue el propuesto para la Vicesecretaría de Información de la Conferencia Episcopal creada en octubre de 1984, y que recoge algunas de las funciones de la extinta agencia Prensa Asociada ${ }^{64}$. La labor que a partir de ese momento realizará el sacerdote y periodista $D$. Joaquín Luis Ortega al frente de ese organismo de Comunicación Institucional de la Conferencia Episcopal Española puede considerarse como modélica, incluso a tenor de los resultados.

En el documento mecanografiado y sin firma: Notas para la estructuración de la Vicesecretaria de la CEE para información, fechado en Madrid a 21 de noviembre de $1984^{65}$, se explicita el desarrollo de este organismo. En el apartado de las consideraciones previas se define la Vicesecretaría para la Información como:

63 Ibid., 5.

64 Boletin del Secretariado, 106, 1984, 1.12 noticia dice asi: Con el propósito de incrementar los servicios informativos de la Conferencia Episcopal y hacer más presente a la Iglesia de España en el ámbito de la Opinión Pública, el Obispo presidente de la Comisión Episcopal de Mectios de Comu. nicación Social y el Secretario General del Episcopado, Monseñones Montero y Sebastín, han propuesto conjuntamente a la Comisión Permanente la creación de una nueva Vicesecretaria para la Información -que se añade a las dos preexistentes, de Asuntos Generales y de Economia, regidas respectivamente por D. José M." Eguarás y D. Bernardo Herriez.

En el nuevo organismo se articularán los servicios ya existentes del Secreariado de la Comisión Episcopal de Medios de Comunicación y la Oficina de Información del Episcopado, al par que algunas actividades realizadas hasta ahora por la agencia "Prensa Asociada". Constituira una plataforma informativa de largo alcance, impulsora y coordinadora de las obras y tareas nacionales de la lglesia en el campo de la prensa, la radio, el cine y la televisión, y en estrecho contacto con las Detegaciones Diocesanas de Medios de Comunicación Social. El titular de la Vicesecretaría será el portavoz de las actividades ordinarias del Episcopado. Los servicios de este nuevo organismo iniciaran su funcionamiento en enero de 1985

Para el nuevo cargo ha sido designado el sacendote burgales, D. Joaquín Luis Ortega, de cincuenta y un años, director de Ecclesta....

65 Notas para la Estructuración de la Vicesectetaría de la CEE para Información, Documento pro-manuscripto multicopiado, $6 \mathrm{pp}$. 
un organismo o instrumento de la CEE que, vinculado a la Secretaría General junto a las otras dos Vicesecretarías existentes, se ocupa del planteamiento y de la realización de la política informativa de la CEE.

1.2. Su existencia no contradice ni anula la del Secretariado de Medios de Comunicación Social. A éste, en dependencia directa de la Comisión Episcopal de MCS y bajo su dirección, le corresponde planificar y desarrollar cuanto se refiere a la acción pastoral de la Iglesia a través de los MCS o incluso en ellos mismos.

1.4. La diversidad de funciones y actividades que se integran en la nueva Vicesecretaría y el servicio a la actualidad que suele marcar el ritmo de trabajo de forma un tanto imprevisible y a veces absorbente, recomienda que todas las actividades o secciones de esta Vicesecretaria cuenten con su responsable directo, quedando el vicesecretario más disponible para las tareas de portavoz que se le asignan y menos delegables, para el contacto directo con los medios y para dar respuesta a las eventualidades que se presentan con la debida prontitud. Nótese que en este terreno la urgencia, la anormalidad o la improvisación pueden convertirse en habituales, requiriendo respuestas y soluciones pertinentes que difícilmente podrian darse o que habría que darlas con perjuicio del normal desarrollo de las tareas habituales que realicen las distintas secciones encuadradas en la Vicesecretaria. ${ }^{6}$.

La Vicesecretaria se articula en cuatro secciones: Oficina del Portavoz (Relaciones Públicas), Oficina de Información, Agencia de Noticias y Colaboraciones y Secretariado de Medios de C. Social. Del apartado sobre la Oficina del Portavoz, después de indicar la peculiaridad del artículo 50 de los Estatutos de la CEE y advertir que es la tarea menos delegable, se indican las siguientes tareas específicas:

- Declaraciones de viva voz a los MCS.

- Convocatoria de ruedas de Prensa.

- Comunicados por escrito.

- Comparecencia en los MCS.

- Atención a las demandas habitualmente presentadas por los profesionales.

Funciones complementarias a las anteriores serian:

- Preparación habitual de "encuentros" entre obispos y exponentes de la vida politica, cultural, de los MCS, etc. 
- Creación y mantenimiento de puentes y cauces informativos en los distintos sectores de la sociedad.

- Colocación tempestiva de articulos, opiniones, etc., en los distintos MCS en apoyo de campañas o intereses de la CEE, así como negociación de obispos, té́logos, etc., en los MCS.

- Atención específica a los MCS de titularidad de la CEE (EDICA, COPE, ECCLESIA) mediante presencia institucional en sus respectivos órganos.

N.B. Algunas de las funciones apuntadas, con el tiempo, cabría traspasárselas a una posible oficina de Relaciones Públicas. Sus tareas, aunque muy relacionadas con la política informativa de la Vicesecretaria, podrian diferenciarse orgánicamente ${ }^{6}$ ?

A la Oficina de Información le quedarian las siguientes competencias:

*Ad intra:

- Seguimiento y clasificación de la información religiosa y general en periódicos y revistas para su posterior vehiculación hacia los obispos, los órganos de la Conferencia, etc.

- Análisis y discernimiento de la opinión pública en sus grandes coordenadas. Tarea ésta que podria dar origen a un gabinete especializado encuadrado bien en esta Oficina bien en la posible Agencia de que se habla en el apartado siguiente.

- Confección de la actual revista de Prensa que se envia a los obispos.

- Confección del Boletin de ta CEE.

- Confección de "dossiers" informativos para los MCS.

- Atención a los servicios de "telex".

Ad extra:

- Distribución de notas, comunicados, etc.

- Vehiculación hacia los MCS de la masa informativa generada por la propia Iglesia, la CEE o sus organismos e Instituciones.

- Distribución de informes o "dossiers" a profesionales o MCS. 68.

- Publicación de los estatutos del Servicio para la Información y los medios de comunicación de los obispos del sur de España (ODISUR), aprobados por la Conferencia Episcopal de las Provincias Eclesiásticas de Granada y Sevilla el 17 de octubre de $1988^{69}$. Según sus estatutos, es un óngano del Secretariado General de los Obispos de las provincias eclesiásticas

69 Boletin del Secretariado, 145, 1988, 7-9. 
de Granada y Sevilla, para el quehacer informativo de la Iglesia y para la pastoral de los Medios de Comunicación en el ámbito de las diócesis integradas en ambas provincias eclesiásticas. ${ }^{70}$.

- Los prelados españoles vuelven a abordar en la LVI Asamblea Plenaria el tema de los MCS (18-23 de mayo de 1992). Mons. Martí Alanis, entonces presidente de la Comisión Episcopal de MCS, hacía el siguiente balance de la situación de las Delegaciones de MCS:

(Después de recordar la recomendación de la plenaria del 78 ya citada). Según nuestras informaciones, desde entonces ha mejorado sensiblemente la situación en bastantes diócesis, pero nuestro juicio global es que en la mayor parte sigue siendo conveniente un esfuerzo de reorganización más eficaz. Hay bastantes diócesis en las que el director tiene una dedicación muy limitada, su equipo personal está muy poco profesionalizado, se disponen de locales insuficientes, no se tiene estatuto propio, no se cuenta con presupuesto suficiente y se organizan muy pocas actividades formativas. Otro problema que tienen la mayoria de las diócesis es la inexistencia de un portavoz oficial, función que es asumida por personas diferentes, a veces sin estatuto público y, por tanto, con serias dificultades para asegurar, en momentos decisivos, una correcta comunicación.

Procurar la preparación profesional de algún sacerdote y algún laico, asegurar las comparecencias oportunas, contestar las agresiones, son objetivos que todos deberíamos cubrir. En el campo de la educación, tanto de las actitudes críticas de los fieles, como de un mínimo saber hacer de los agentes de pastoral, hay también mucho que hacer, asi como en la atención pastoral a los profesionales de la comunicación. ${ }^{71}$.

- Meses después los delegados diocesanos de MCS se reúnen en Madrid (3-4 noviembre de 1992) con la pretensión de analizar la situación de las Delegaciones y presentar como modelos una serie de planes de pastoral. Una encuesta a las Delegaciones diocesanas preparó esta Asamblea. Su autor nos ofrece las claves: .Para obtener una idea de la penuria en que se mueven los servicios informativos existentes, nos referiremos a un cuestionario dirigido a sesenta y siete responsables de estos servicios en España durante el mes de marzo del año pasado. Fue elaborado por quien les habla y distribuido por la Conferencia Episcopal... El perfil genérico de estos servicios resulta así: Carecen de regulación juridica; son clericales; sus directivos tienen una formación específica, una dedicación y unos sueldos muy 
escasos; muchos de ellos carecen de colaboradores que, cuando existen, son voluntarios; los medios de producción y distribución son artesanales, lo que repercute negativamente en la penetración en los medios más influyentes y en el seguimiento de la misma información emitida. Todo ello no obsta para que las relaciones de estas personas con los profesionales de los medios suelan ser excelentes ${ }^{72}$.

\subsection{Las Delegaciones Diocesanas de Medios de Comunicación Social}

Rastrear el proceso de creación de las Delegaciones diocesanas de MCS en nuestro pais no ha sido tarea fácil por la escasez de fuentes documentales y bibliográficas sobre esta materia. Los Boletines Oficiales de las diócesis aparecieron, en un primer momento, como nuestros únicos aliados. Después descubririamos que las publicaciones oficiales mantenian, por lo general, el más absoluto silencio. Tampoco los archivos del Secretariado de la Comisión Episcopal de Medios nos ofrecieron excesivas claves. Ante la precariedad de material nos vimos obligados a recumir directamente a las Delegaciones, mediante una encuesta por correo. Enviamos la primera carta a los delegados diocesanos de MCS el 15 de febrero de 1994. Después de explicar el motivo de nuestro estudio y los pasos ya dados, les pedíamos los siguientes datos:

1) Fecha completa y oficial de constitución de la Delegación.

2) Si en su diócesis hubiera habido anteriormente algún organismo similar, cuál era su denominación, fecha de constitución, características.

3) Decreto de constitución de la Delegación y estatutos o reglamento de la misma. Si es posible, indíquenos la referencia de su publicación en el Boletin Oficial de la Diócesis, o envienos una fotocopia del mismo.

4) ¿De qué organismo de la curia diocesana depende o está encuadrado organizativamente?.

Las respuestas recibidas en esta primera fase fueron escasas: 20, de 67 encuestadas. Ante lo que pensábamos que era una descuido, que se unia al trabajo de estos organismos siempre necesitados de medios, recurrimos el 19

72 G. Raigón Pérez de la Concha, 'Comunicación y Pluralismo en la actividad medítica', en M." T. Aubach (coord.), Comunicación y Pluralismo. Actas del I Congreso Internacional (25-27 de noviembre de 1993), Salamanca 1994, 592-593. 
de abril de 1994, de nuevo, al correo con una breve misiva que recogía las preguntas formuladas por la anterior. Se enviaron 47 cuestionarios; recibimos 10 respuestas más ${ }^{73}$. Como luego podremos observar no existe con claridad un tipo de Delegación o de delegado que contesta a nuestras preguntas. Tal vez podamos inferir que han sido aquellos que tienen más medios o se plantearon alguna vez nuestros interrogantes quienes estuvieron más capacitados para responder.

Metodológicamente vamos a consignar toda la información que poseemos acerca de cada una de las Delegaciones diocesanas sobre cinco grandes apartados: Fecha de constitución, Denominación actual, Organismo precedente si lo hubiera tenido, Decretos y Estatuto de Constitución y de quién depende en la Curia diocesana. Para analizar estos datos utilizamos las siguientes fuentes, que numeramos así:

1. Datos obtenidos en el Boletin Oficial de la Diócesis.

2. Otros datos que aparecen en documentos del Secretariado de la Comisión Episcopal de Medios de Comunicación o en sus publicaciones:

a) Boletin del Secretariado, crónica de la reunión de Delegados de 1974.

b) Encuesta del Secretariado de la Comisión Episcopal de Medios de Comunicación con fecha de 25 de mayo de 1992.

3. Datos obtenidos mediante nuestro cuestionario.

Al lado del nombre de cada una de las diócesis aparecerá la fecha de constitución que viene consignada, no en todos los casos, en la Guia de los Medios de Comunicación de la Iglesia Española ${ }^{74}$.

73 En total recibimos 30 respuestas de las siguientes diócesis (por orden de llegada): Astorga, Burgos, Vitoria, León, Siguienza, Lugo, Tuy-Vigo, Granada, Ávila, Orense, Santiago, Jerez de la Fronuera, Coria-Cáceres, Tarazona, Bilbao, Nicante, Santander, San Sebastián, Ciudad Real, Zamora, Huesca, Jaca, Tortosa, Mallorca, Badajoz, Logroño, Barbastro, Vich, Osma-Soria y Málaga.

Quiź nas sirva de consuelo pensar que en el Primer Congreso de Comunicación Corporativa (Madrid, 5 y 6 de mayo de 1994) se presentaron los datos de un estudio, realizado mediante un cuestionario, dirigido a las personas con responsabilidad directa en comunicación interna de las 215 primeras empresas españolas. Las respuestas fueron 111, un $48 \%$. Alberto Andreu Pinillos, director del estudio, califico este nivel de muy elevado en este tipo de estudios. Nosotros, que llegamos a un $40 \%$, nos damos por satisfectios y agradecemos a todos su trabajo.

La Comisión Episcopal de Medios de Comunicación realizo una encuesta, que más tarde estudiaremos, 2 las 67 diócesis españolas sobre sus Delegaciones de Medios de Comunicación Social. Se recibieron un tonl de 52 respuestas ( 77 \%).

74 Oficina de Estadistica y Sociologia de la Iglesia Española, Guia de los Medios de Comunicación de la tglesia Españala, Madrid 1986. 


\section{DIOCESES ESPANTOAS}

Albacete:

2. a) El único dato obtenido es una referencia a la presencia de esta diócesis en la reunión de delegados de 1974.

b) En la actualidad se denomina Delegación Episcopal, sin estatutos; su responsable aparece como delegado.

\section{Almeria:}

1. En el Boletín de la Diócesis de noviembre-diciembre de $1986^{75}$, aparece la noticia de la constitución de la Delegación.

2. a) Asistió a la reunión de $\mathbf{1 9 7 4}$.

b) No se tienen más datos (no contestó a la encuesta de 1992).

\section{Alcalá:}

2. b) Diócesis de reciente creación, tiene una Delegación Episcopal, con un delegado al frente y sin estatutos.

Astorga (1960):

2. a) Asistió a la Reunión de 1974 .

b) La Delegación diocesana tiene un delegado al frente y sin estatutos.

3. Contestó a nuestra encuesta con un proyecto de Delegación, sin fecha, centrado en las actividades en la COPE local: programas -El Rastro de Dios,, Quince minutos misionales...

Ávila (1953):

2. a) No tenía delegado en 1974.

b) Se denomina Delegación diocesana; el responsable es el delegado diocesano, y no tiene estatutos.

3. La primera fecha de nombramiento oficial de delegado es de $\mathbf{1 9 7 5}$, en la persona de D. Agapito Díaz Cabrera, por el entonces administrador apostólico Ilmo. D. Julián Blázquez Chamorro. 
Badajoz:

2. a) Excusó la asistencia a la reunión de 1974.

b) Tiene un Secretariado diocesano de Medios de Comunicación Social, con un director al frente. No tiene estatutos.

3. Oficialmente se constituyó el Secretariado Diocesano con el nombramiento, el 8 de marzo de 1993, de su director. Depende de la Vicaría de Evangelización y no tiene estatutos. En su constitución oficial ha jugado un importante papel el Sinodo Pacense de 1992.

Barbastro:

2. a) Asistió a la Reunión de 1974 .

b) La Delegación diocesana tiene una Oficina diocesana de Información; al frente está el delegado diocesano. No tiene estatutos.

3. El primer delegado del que hay constancia oficial es D. José Maria Ferrer Muñoz, nombrado el 31 de octubre de 1986. Depende de la Vicaría de Pastoral.

Barcelona (1956):

1. En febrero de 1991 aparece el Decreto de Reforma de la Delegación Diocesana.

2. a) Asistió a la Reunión del 74 .

b) No contestó a la encuesta de 1992.

\section{Bilbao:}

2. a) Asistió a la Reunión de 1974 .

3. Existe el Secretariado de Medios de Comunicación desde 1972. El 15 de diciembre de 1993 se erige oficialmente la Delegación Diocesana de Medios de Comunicación, dependiente de la Vicaría General. En su constitución tuvo un importante papel la Asamblea Diocesana celebrada los años 1984-1987.

El Decreto de constitución, con los estatutos, son los siguientes:

D. LUTS MARIA DE LARREA Y lEGARRETA, POR LA GRACIA DE DOOS Y DE LA SANTA SEDE APOSTOLICA, OAISPO DE BHBAO.

La Iglesia, especialmente desde el Pontificado de Pío XI, tomó conciencia de la importancia singular de los medios de comunicación y de la significacion que estos tienen para el cumplimiento de la misión eclesial. 
Documentos como el Decreto Conciliar Inter Mirifica (4 de diciembre de 1963), las Instrucciones pastorales Communio et Progressio (27 de mayo de 1971) y Aetatis Novae (22 de febrero de 1992) marcan las grandes orientaciones sobre el pensamiento de la Iglesia en este campo de los medios de comunicación. También son significativos los criterios pastorales sobre las comunicaciones sociales, que surgen de las Asambleas Plenarias del Episcopado Español de junio de 1978 y de mayo de 1992.

En nuestra diócesis, desde el pontificado de mi predecesor Mons. Antonio Añoveros, existe un Secretariado de Medios de Comunicación, aunque sin estar jurídicamente constituido.

La Asamblea Diocesana (1984-1987) recogió en sus conclusiones "la notable importancia de los medios de comunicación en la vida real, en la formación de la nueva cultura, en la configuración del nuevo tipo de cristiano adulto, en la transmisión de la imagen de la iglesia y en las posibilidades de evangelización".

Con posterioridad, en el tercer objetivo específico, primera acción recomendada, del Plan Diocesano de Evangelización (1990-95), se señala que "puesto que la comunicación es signo y vehículo de comunión, parroquias, sectores, vicarías, organismos autónomos y Obispado, informarán, asesorados por la Delegación Diocesana de Medios de Comunicación Social, al conjunto de la diócesis y a la sociedad acerca de sus principales actividades y acontecimientos, a través de distintos canales de comunicación propios y ajenos".

Para responder mejor a las necesidades de la evangelización de nuestro tiempo, y a las grandes posibilidades y retos que plantean los medios de comunicación, tras los estudios y consultas pertinentes y oído el Consejo Episcopal,

\section{DECRETO}

Constituir en nuestra Curia diocesana la Delegación Diocesana de Medios de Comunicación Social, ya existente de hecho, y que se regirá por las siguientes

NORMAS

Artículo 1. La Delegación Diocesana de Medios de Comunicación Social es un organismo técnico de la Curia diocesana en el campo de la comunicación social y sus medios, que depende organicamente del vicario general. Articulo 2. Son funciones de la Delegación Diocesana de Medios de Comunicación orientar, promover y coordinar la evangelización de los medios y la evangelización por los medios, y en particular:

1. Procurar e incrementar una presencia fiel y digna de los mensajes de la Iglesia, de sus instituciones, de sus pastores, de las comunidades cristianas, en los medios de comunicación, a través de la Oficina de Prensa.

2. Estar presente y colaborar en la planificación de la programación religiosa de las emisoras de radio de titularidad diocesana, y acompañar a la 
dirección y a la redacción de las mismas en la observancia de su propio Ideario.

3. Acompañar pastoralmente a los periodistas cristianos de la diócesis, prestando especial atención a los periodistas jóvenes y estudiantes de Ciencias de la Información.

4. Potenciar la comunicación interna dentro de la comunidad diocesana, fomentando la comunión, la corresponsabilidad y la opinión pública.

$5 .^{\circ}$ Editar el Boletín Oficial del Obispado y otras publicaciones diocesanas que puedan set de interés general, además de asesorar las de otros organismos y movimientos de carácter diocesano.

6. Proporcionar información al obispo sobre hechos y acontecimientos eclesiales y sociales de los que deba estar informado.

7..$^{\circ}$ Asesorar a la Curia diocesana y a otros organismos, como consejos diocesanos, movimientos apostólicos y asociaciones, en la elaboración de Jornadas y Campañas.

8. Orientar la creación de comisiones de información en parroquias, sectores y vicarias, que fomenten la comunicación interna en las distintas comunidades.

9. Promover la formación de los usuarios de la comunicación, prestando especial atención a los agentes de pastoral y personas encuadradas en asociaciones eclesiales y movimientos apostólicos, escuelas sociales y otros.

10. Mantener la coordinación y colaboración, tanto en el intercambio de información como de proyectos conjuntos, con las Delegaciones de Medios de Comunicación Social (MCS) de las diócesis de Euskalerría, el Secretariado Interdiocesano y el Secretariado de la Comisión Episcopal de MCS.

11. Diseñar periódicamente un Plan diocesano de Comunicación desde la clave de las prioridades pastorales diocesanas, y programar las actividades propias de cada curso.

Articulo 3. Al frente de la Delegación Diocesana de Medios de Comunicación Social habra un delegado, nombrado por el obispo, y dotado de potestad ejecutiva delegada para los fines propios de su encomienda. El período de mandato será de seis años, pudiendo, a su vencimiento, ser nuevamente designado.

Artículo 4. La Delegación Diocesana de Medios de Comunicación Social constará de las siguientes secciones:

a) Oficina de Prensa, a la que corresponderá la responsabilidad de la portavocia diocesana, en los casos que así lo decida el obispo. También son funciones de esta Oficina de Prensa la convocatoria de ruedas de prensa, el envío de información a los medios y el contacto con los medios de comunicación.

b) Sección de Publicaciones. A ella comesponde la edición del Boletin Oficial det Obispado, de las publicaciones y hojas periódicas que edite la Dele- 
gación de MCS, el asesoramiento técnico a publicaciones de otros ámbitos diocesanos y a las Jornadas y Campañas que se organicen.

c) Acompañamiento pastoral y formación. Esta sección es la responsable de orientar cristianamente a profesionales de la información y a futuros informadores, así como de la formación de los usuarios.

d) Archivo y Documentación. A esta sección le corresponde realizar el resumen diario y semanal de prensa, el archivo de imágenes, videoteca y archivo de documentación.

e) Servicio de Audiovisuales. A esta sección le corresponde crear, confeccionar y facilitar materiales para la acción pastoral de la Diócesis. Desde este servicio se ofrecen también cursillos de formación y aprendizaje para la urilización de estos medios por los agentes de pastoral.

Artículo 5. El presupuesto anual de la Delegación Diocesana de Medios de Comunicación Social, asi como el nombramiento y estatuto de su personal, se ajustará a los criterios y normas establecidas al respecto para la Curia diocesana en todos sus organismos.

Artículo 6. Las presentes normas tendrán carácter experimental durante un año.

Dado en Bilbao, a quince de diciembre de mil novecientos noventa y tres. t Luis Maria de Larrea, Obispo de Bilbao.

Por mandato del Sr. Obispo, Carmelo Ibarra Canciller.

\section{Burgos (1965):}

2. a) Excusó su asistencia a la Reunión de 1974.

b) Tiene Delegación Diocesana, con un delegado diocesano al frente, sin estatutos.

3. Se constituyó como tal en octubre de 1980. La Secretaría del Arzobispado asumió en tiempos pasados alguna de sus funciones. Respecto a la dependencia orgánica, transcribimos la contestación por lo inusual de la misma:

.4. Actualmente (desde 1993) la Delegación Diocesana de Medios depende de la Oficina de Comunicación del Arzobispado de Burgos. Estando estnucturado el tema de relación con los Medios de la siguiente manera:

- Portavoz oficial del Arzobispado: el vicario general.

- Oficina de Información: Un director (en este caso, periodista laico).

- Delegación de Medios de Comunicación Social: al frente de la cual está un delegado diocesano (sacendote).

Las competencias de la Oficina de Información y de la Delegación de Medios son la elaboración de programas de Radio y elaboración de publicacioner diocesanas y comunicados oficiales, así como la relación directa 
con los Medios de Comunicación locales y nacionales, y la moderación técnica de ruedas de prensa.

Cádiz-Ceuta (1988):

2. a) No contestó a la invitación de la Reunión de 1974.

b) Tiene Delegación Episcopal y dice tener estatutos en la encuesta de 1992.

Calaborra-Logroño (1988):

2. a) Asistió a la Reunión de 1974 .

b) Tiene Delegación Episcopal y su responsable es delegado episcopal.

3. La Delegación inició su funcionamiento al principio de los años 60 , con el nombramiento como responsable de estas tareas a S. Gil de Muro Quiñones, en el gobiemo diocesano de D. Abilio del Campo y de la Bárcena. A la Delegación se le dota de un Reglamento en el gobiemo de D. Francisco Álvarez Martínez, con un proyecto presentado al Consejo presbiteral en junio de 1979. Depende de la Delegación de Enseñanza, antes como Secretariado de la Vicaría de Pastoral. El proyecto de Estatutos que nos remiten es similar al proyecto de Estarutos publicado en el Boletin del Secretariado en octubre de 1978.

\section{Canarias (1968):}

2. a) No contestó a la invitación de la Reunión de 1974.

b) Tampoco contestó a la encuesta de 1992.

\section{Cartagena-Murcia:}

2. a) No contestó a la invitación de la Reunión de 1974.

b) Tiene Delegación Episcopal y Oficina de Información del Obispado; al frente está el delegado diocesano.

\section{Ciudad Real (1966):}

2. a) Asistió a la Reunión de 1974.

b) Se denomina Secretariado Diocesano de Medios de Comunicación Social.

3. El Secretariado se creó el 31 de octubre de 1966, y fue reestructurado por decreto de 29 de septiembre de 1977 . No tiene estatutos, 
y depende de la Vicaría General como Delegación y de la Secretaría General del Obispado como Oficina de Prensa. No hubo organismo anterior.

Ciudad Rodrigo (1970):

2. a) Asistió a la Reunión de $\mathbf{1 9 7 4 .}$

b) Tiene Delegación Diocesana, con un delegado diocesano al frente. No tiene estatutos.

Córdoba:

2. a) Asistió a la Reunión de $\mathbf{1 9 7 4 .}$

b) Tiene Delegación Episcopal y Oficina de Información Diocesana. El responsable es el delegado episcopal. No tiene estatutos.

Coria-Cáceres:

2. a) Excusó su asistencia a la reunión de 1974 .

b) Tiene una Delegación diocesana, con un delegado diocesano al frente.

3. Depende del Vicariato de Asuntos Jurídicos, Sociales y Económicos, y se rige por los estatutos comunes de las Delegaciones Episcopales Diocesanas conferidos por Mons. Jesús Dominguez Gómez, el 27 de septiembre de 1989.

Cuenca (1970):

2. a) No contestó a la invitación de la Reunión de $\mathbf{1 9 7 4}$.

b) Tiene Delegación diocesana, con un delegado al frente, sin estatutos.

Gerona:

2. a) En 1974 no tenia delegado.

b) Su organismo se denomina Delegación diocesana, con un delegado al frente.

Getafe:

2. Diocesis de reciente creación. 
Granada:

2. a) Asistió a la Reunión de 1974 .

b) Tiene Delegación diocesana, con un delegado al frente.

3. La fecha de constitución de la Delegación es de agosto de 1992. Depende onganizativamente de la Secretaría General.

Guadix-Baza (1979):

2. a) En 1974 no tenía delegado.

b) Tiene Delegación diocesana, con un delegado al frente.

Huelua:

2. a) Excusó su asistencia a la Reunión de 1974.

b) No contestó a la encuesta de 1992.

Huesca (1985):

2. a) No contestó a la invitación de la Reunión de 1974.

b) Tiene Delegación diocesana, con un delegado al frente y sin estatutos.

3. La respuesta a nuestro cuestionario fue la siguiente:

-En una diocesis como la nuestra es muy dificil que su estructura de funcionamiento responda a esquemas amplios y ambiciosos.

Ha habido desde hace muchos años:Boletin Oficial del Obispado y Hoja Parraquial Dtocesana, con dos personas distintas al frente de esos servicios.

Después se introdujo un programa de Servicios Religiosas, a través de Radio Huesca, primero con guiones originales, después con celebración de la Eucaristia; en la actualidad, solamente con alguna noticia y algún breve comentario los domingos.

El 13 de febrero de 1985 se coordinan estas responsabilidades en la llamada Oficina de Información o Delegación Diocesana de Medios de Comunicación Social, en la que se integran los responsables de esos servicios...

Esto es to que puedo decir. Un saludo, Agustín Catón, Vicarioo.

Ibiza:

2. a) No contestó a la invitación de la Reunión de 1974 .

b) No contesto a la encuesta de 1992. 
Jaca:

2. a) No contestó a la invitación de la Reunión de 1974.

b) Tiene Delegación diocesana, con un delegado al frente.

3. La contestación a nuestro cuestionario fue la siguiente:

-Muy estimado Sr:

Me apresuro a dar contestación a su carta, en la que pide fecha completa y oficial de constitución de la Delegación de Medios. Pues bien, no consta oficialmente, pero el delegado de Medios lleva al frente de dicha delegación nueve años. Anteriormente existia un responsable de prensa o secretariado. Tampoco existe decreto de constitución de la Delegación y estatutos o reglamento de la misma.

El organismo de la curia, del cual depende, es la Delegación de Medios de Comunicación Social.

Lamento no poder dar datos más precisos. Le saluda cordialmente, Alfredo Giménez.

Jaén:

2. a) Excusó su asistencia a la Reunión de 1974.

b) Tiene Delegación Episcopal, con un delegado al frente, sin estatutos.

Jerez de la Frontera (1986):

2. a) No existía como diócesis en $\mathbf{1 9 7 4 .}$

b) Tiene Delegación diocesana, con un delegado al frente, sin estatutos.

3. La fecha de Constitución de la Delegación fue el 29 de junio de 1980. Anteriormente dependia de Sevilla. Según la respuesta recibida: :No depende de ningún organismo de la curia diocesana. Es independiente.

León:

2. a) No contestó a la invitación de la Reunión de $\mathbf{1 9 7 4 .}$

b) Tiene Secretariado diocesano de Medios de Comunicación, con un director del Secretariado al frente.

3. Se constituyó a partir del año 1981, cuando tuvo lugar una reestructuración de los servicios pastorales diocesanos. A finales de 
1991 se le dio un estatuto marco. Organizativamente el Secretariado está encuadrado en la Delegación de Medios de Comunicación, pero no existe ni Delegación ni delegado. Según el Estatuto, el Secretariado es un organismo de índole pastoral e instrumental que, dentro de la Delegación de Comunicación Social, con la autoridad delegada del obispo, se responsabiliza de procurar que la conciencia de los fieles se forme rectamente sobre el uso de estos medios y también de estimular y organizar todo lo que la diócesis y los diocesanos realicen en este campo. Igualmente será de su responsabilidad coordinar este apostolado en la diócesis y preparar la celebración de la Jornada de las Comunicaciones Sociales. Las funciones del Secretariado son:

.1.2 Representar la voz del obispo y de la diócesis ante la opinión pública.

2.2 Atender a la vida cristiana de los profesionales de los medios de comunicación social residentes en la diócesis.

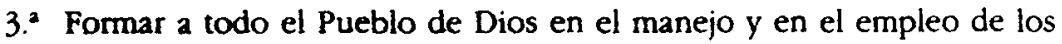
medios de comunicación.

4." Recibir y canalizar las informaciones eclesiales que convenga.

5. Coordinar el trabajo pastoral que, en este campo, se lleve a cabo en la diócesis.

6. Facilitar los datos de la vida de la Iglesia que se le soliciten.

Los Estatutos incluyen una serie de acciones detalladas y unos instrumentos al servicio de este departamento (medios técnicos y humanos). En el capítulo de los Órganos propios dice lo siguiente:

-Para poder cumplir su misión, el Secretariado contará con los siguientes órganos personales o colegiados:

1. El director del Secretariado, sobre quien recae la responsabilidad máxima del funcionamiento del mismo.

2. El equipo diocesano de MCS.

3. El equipo de asesores profesionales de los MCS.

4. El equipo de colaboradores.

Lérida (1972):

2. a) No contestó a la invitación de la Reunión de 1974.

b) Tiene Delegación diocesana, con un Delegado al frente, sin estatutos. 
Lugo (1924):

2. a) No contestó a la invitación de la Reunión de 1974 .

b) Tiene Secretariado Diocesano de Medios de Comunicación Social, con un director del Secretariado al freate, sin estatutos.

3. En la década de los 20 se nombra un responsable de relaciones con la prensa. la primera referencia oficial al Secretariado aparece en la Estadística Diocesana de 1968.

\section{Madrid:}

2. a) Asistió a la reunión de 1974 .

b) Tiene Oficina de Prensa e Información, con un director de la Oficina al frente, sin estatutos.

Málaga (1974):

2. a) Asistió a la Reunión de 1974.

b) Tiene Delegación diocesana, con un delegado al frente, sin estatutos.

3. No consta fecha de creación de la Delegación. Sí consta que funciona desde 1969. Actualmente está integrada en la Oficina de Prensa del Obispado, dependiendo de la Secretaría General.

Mallorca (1969):

2. a) Asistió a la Reunión de 1974.

b) Tiene Delegación diocesana, con un delegado al frente, sin estatutos.

3. Desde 1958 había una Comisión Diocesana de Radiodifusión con el encargo de crear la emisora diocesana de Radio Popular (1959). El 30 de abril de' 1974, Mons. Teodoro Úbeda Gramage crea, mediante un Decreto de Constitución, la Comisión Diocesana de Medios de Comunicación Social, después de unos años de experiencia y aportando una organización que antes no tenia. La actual Delegación depende de la Vicaria General.

\section{Menorca:}

2. a) No contestó a la invitación de la Reunión de 1974 .

b) No contestó a la encuesta de 1992. 
Mondoñedo-Ferrol (1970):

2. a) No contestó a la invitación de la Reunión de 1974.

b) Tiene un Gabinete de Prensa, con un director al frente, sin estatutos.

Orense (1972):

2. a) No tenía delegado en 1974 .

b) No contestó a la encuesta de 1992.

3. No hay Decreto de constitución oficial de la Delegación ni estatutos. El primer delegado nombrado oficialmente lo fue con fecha de 1 de enero de 1974. Depende del Sr. obispo. El vicario de pastoral coordina los programas de las delegaciones.

\section{Oribuela-Alicante:}

2. a) No contestó a la invitación de la Reunión de 1974 .

b) No contestó a la encuesta de 1992.

3. El Secretariado Diocesano de Medios de Comunicación se constituyó en julio de 1990, tras la toma de posesión de Mons. Francisco Álvarez Martínez. Aparece ya en el organigrama de la Curia en julio de 1990. Anteriormente existía una Oficina de Prensa del Obispado erigida en 1966, después del Concilio. Se encuadra en la Curia de Pastoral. Aparece en un breve documento la naturaleza de Secretariado.

Se concibe, dentro de la organización diocesana, como un servicio pastoral de la Iglesia en el campo de la comunicación y los medios.

Dentro de los fines se especifican:

-1. Promover la difusión del mensaje cristiano a través de los medios de comunicación social.

2. Pacilitar a la opinión pública información sobre la vida, actividad y doctrina de la Iglesia universal y diocesana.

3. Estimular, promover y coordinar la actividad de los católicos en el campo de la comunicación.

4. Fomentar la formación de los agentes de pastoral en los medios de comunicación.

5. Prestar atención pastoral a los profesionales de los MCS, apoyada sobre todo en el plano de la amistad y colaboración. 
Osma-Soria (1988):

2. a) No tenía Delegación en 1974 .

b) Cuenta con una Delegación diocesana, con un delegado al frente, sin estatutos.

3. Se constituye oficialmente en enero-febrero de 1989. No existe referencia de fecha exacta, ni de estatutos o reglamento. En 1986 Mons. José Diéguez Reboredo nombró, el 7 de diciembre, un Equipo Diocesano de Medios de Comunicación Social. La Delegación depende del obispo, y elabora un Plan diocesano conjunto con el resto de organismos.

Oviedo (1963):

2. a) Asistió a la Reunión de 1974 .

b) Tiene un Secretariado Diocesano de Medios de Comunicación, con un director al frente, sin estatutos.

Palencia:

2. a) No tenía delegado en $\mathbf{1 9 7 4}$.

b) No contestó a la encuesta de 1992.

Pamplona:

2. a) Asistió a la Reunión de 1974 .

b) Tiene, en una estructura compleja, Delegación diocesana de Medios de Comunicación, Secretariado diocesano de MCS y Oficina de Prensa. Los responsables son el delegado diocesano y el director del Secretariado. Aparece, sin especificar, un Decreto fundacional no encontrado.

Plasencia:

2. a) No tenía Delegación en 1974.

b) Ahora cuenta con una Delegación Episcopal, con un delegado al frente, sin estatutos.

Salamanca (1963):

2. a) No contestó a la invitación de la Reunión de 1974.

b) Cuenta con una Delegación diocesana, con un delegado al frente, sin estatutos. 
San Sebastián (1982):

2. a) No contestó a la invitación de la Reunión de 1974.

b) Tiene una Delegación diocesana, con un delegado al frente, sin estatutos.

3. La respuesta a nuestras preguntas fue la siguiente:

-A la atención de D. Federico R. Aznar Gil.

En esta ciudad sin coso taurino desde que lo derribaron ilustres urbanistas, me ha pillado el toro. Es una de las razones por las que no contesté a su debido tiempo a su petición de datos.

La segunda razón es que apenas tenemos alguno de los que Ud. solicita. No consta en los boletines de la diócesis nada sobre la fecha de nacimiento de algo que pudiera ser antecedente de la Oficina de Medios de Comunicación Social tal como hoy se la concibe y funciona.

Sí puedo decir que, organizativamente, depende de la Secretaría General. Decididamente, no valemos para hacer historia; nos limitamos a vivir el cada día. No es respuesta muy académica, pero sí absolutamente cierta y real.

Firmado: Miren Jone Azurza.

Santander (1975):

2. a) Asistió a la Reunión de $\mathbf{1 9 7 4}$.

b) Tiene Delegación diocesana, con un delegado al frente, sin estatutos.

3. En 1952 aparece en el Boletin de la Diócesis (78-1952) por primera vez el nombramiento de delegado diocesano de Información y Estadística. Se constinuye la Delegación a partir de 1957, con la anterior denominación y el trabajo de D. Francisco Odriozola Argos al frente.

Santiago de Compostela (1985):

2. a) Asistió a la Reunión de 1974.

b) Tiene Delegación diocesana, con un delegado al frente, sin estatutos.

3. En el año de 1964, pórtico del Año Santo Compostelano, el cardenal Quiroga Palacios nombró un delegado diocesano de Prensa e Información y una Comisión diocesana de Cine, Radio y Televisión. Los nombramientos de delegados diocesanos se han sucedido a lo largo de los años hasta la actualidad. El año 1985 se puede considerar como fundacional de la Delegación diocesana de Medios de 
Comunicación. No consta Decreto de constitución ni estatutos. Depende de la Secretaría General del Obispado.

Segorbe-Castellón (1967):

2. a) Asistió a la Reunión de 1974 .

b) No contestó a la encuesta de 1992.

Segovia:

2. a) No contestó a la invitación de la Reunión de 1974 .

b) Tiene Delegación diocesana, con un delegado al frente, sin estatutos.

Sevilla:

2. a) Asistió a la Reunión de $\mathbf{1 9 7 4 .}$

b) Tiene Delegación episcopal, con un delegado al frente, sin estatutos.

Sigüenza-Guadalajara (1982):

2. a) No tenía delegado en 1974 .

b) Cuenta con una Delegación diocesana, con un delegado al frente, sin estatutos.

3. El 15 de febrero de 1982 fue creada en el Decreto de reestructuración de los cargos diocesanos por Mons. Jesús Pla Gandía. Con la llegada de Mons. José Sánchez se redactó un marco orientativo. Depende de la Curia de Pastoral, con el vicario general al frente.

Solsona:

2. a) Excusó su asistencia a la Reunión de 1974 .

b) No contestó a la encuesta de 1992.

Tarazona:

2. a) Asistió a la reunión de $\mathbf{1 9 7 4 .}$

b) Tiene Secretariado diocesano, con un director al frente, sin estatutos.

3. En 1985 se unifica la dirección del Boletin Oficial y de la Hoja Parroquial en una sola persona, el director de Medios de Comuni- 
cación Social, sin nombramiento específico. Luego se han sucedido los nombramientos de facto de directores. No hay estatutos y depende de la Vicaría de Pastoral.

\section{Tarragona:}

2. a) No contestó a la invitación de la Reunión de 1974 .

b) Tiene un Departamento de Medios de Comunicación, con un jefe del Departamento al frente, sin estatutos.

Tenerife:

2. a) No contestó a la invitación de la Reunión de 1974 .

b) Tampoco contestó a la encuesta de 1992.

Teruel-Albarracín (1986):

2. a) No contestó a la invitación de la Reunión de 1974 .

b) Tiene una Delegación diocesana, con un delegado al frente, sin estatutos.

Toledo:

2. a) Asistió a la Reunión de 1974 .

b) No contestó a la encuesta de 1992.

Tortosa (1953):

2. a) Asistió a la Reunión de $\mathbf{1 9 7 4}$.

b) Tiene Delegación episcopal, con un delegado al frente, sin estatutos.

3. Anteriormente existía un Secretariado Diocesano de Cine, Radio y Televisión junto con la Delegación Diocesana de Prensa. No tenemos fechas. Depende de la Vicaría General y de la Secretaria General.

\section{Tuy-Vigo:}

2. b) Tiene Oficina Diocesana de Información, con un director al frente, sin estatutos.

3. El 28 de octubre de 1969 se constituye un delegado episcopal para el Ministerio de la Palabra. La Oficina Diocesana depende del obispo, sin estatuto. Tuvo relevancia en su configuración, a lo largo de 
los años, el Concilio Pastoral de Galicia (1974), en su capítulo sobre Medios de Comunicación.

Urgell (1971):

2. a) Asistió a la Reunión de 1974 .

b) Tiene Delegación diocesana, con un delegado al frente, sin estatutos.

\section{Valencia:}

2. a) Asistió a la Reunión de 1974 .

b) Tiene Delegación diocesana, con un delegado al frente, y sí declara tener estatutos.

\section{Valladolid:}

1. Creación de la Delegación en $1984^{76}$.

2. a) Asistió a la Reunión de 1974 .

b) Tiene Delegación episcopal, con delegado. Sí declara tener estatutos.

Vich:

2. a) Asistió a la Reunión de $\mathbf{1 9 7 4 .}$

b) Tiene Delegación diocesana, con un delegado al frente, sin estatutos.

3. La Delegación diocesana se remonta a la Junta Diocesana de Buena Prensa, luego Prensa e Información de la Iglesia. En 1960, con el nombre de Delegación Episcopal de Radio, Cine y Televisión. En 1968, con el de Medios de Comunicación Social. Depende de la Secretaría del Obispado.

Vitoria (1983):

2. a) Excusó su asistencia a la Reunión de 1974.

b) Tiene Secretariado diocesano de MCS, con estatutos.

3. Se constituyó el 25 de abril de 1983. Tiene como estatutos las propuestas aprobadas por el Consejo presbiteral de abril de 1983 sobre 
la presencia de la Iglesia en los MCS. Depende de la Vicaría de Pastoral.

\section{Zamora (1971):}

2. a) No contestó a la invitación de la Reunión de 1974.

b) No contestó a la encuesta de 1992.

3. El 15 de enero de 1993 es nombrado el primer delegado diocesano de MCS. En febrero de ese año se nombra una Comisión Diocesana de MCS. No ha habido ningún organismo anterior similar. No tiene decreto de constitución, ni estatutos. Depende de la Vicaría General.

\section{Zaragaza:}

2. a) Asistió a la Reunión de $\mathbf{1 9 7 4}$.

b) Tiene Oficina de Información, con un director al frente, sin estatutos.

\subsection{Análisis sistemático}

Después de haber reseñado los datos que tenemos sobre cada Delegación Diocesana de Medios de Comunicación Social vamos a consignar de forma sistemática los aspectos fundamentales referidos a la denominación, constitución y estructura diocesana.

\section{a) Denominactón}

Como hemos podido observar, no existe una uniformidad terminológica. Se descubre una diversidad de nombres fruto de las épocas en las que se constituyeron estos organismos y de las conexiones entre la doctrina canónica y la terminología civil. No abordamos una cuestión baladi. De la forma de nombrar se siguen una serie de consecuencias prácticas. Nos encontramos con las siguientes denominaciones de este organismo:

- Delegación Diocesana de Medios de Comunicación Social: Astorga, Ávila, Barbastro, Barcelona, Bilbao, Burgos, Ciudad Rodrigo, Coria-Cáceres, Cuenca, Gerona, Getafe, Granada, Guadix-Baza, Huesca, Jaca, Jerez de la Frontera, Mallorca, Orense, Palencia, Pamplona, Santander, Santiago de Compostela, Segovia, Sigüenza-Guadalajara, Tenuel-Albarracin, Urgell, Valencia, Valladolid, Vic, Zamora. 
- Delegación Episcopal de Medios de Comunicación Social: Albacete, Alcalá, Cádiz-Ceuta, Calahorra-Logroño, Cartagena-Murcia, Córdoba, Jaén, Lérida, Osma-Soria, Plasencia, Salamanca, San Sebastián, Sevilla, Tortosa.

- Oficina de Prensa: Madrid, Málaga.

- Secretariado Diocesano de Medios de Comunicación Social: Badajoz, Ciudad-Real, León, Lugo, Orihuela-Alicante, Oviedo, Solsona, Vitoria.

- Gabinete de Prensa: Mondoñedo-Ferrol.

- Departamento de Medias de Comunicación Social: Tarragona.

- Oficina Diocesana de Información: Tuy-Vigo, Zaragoza.

Las denominaciones más comunes son las de Delegación Diocesana, Delegación Episcopal y Secretariado Diocesano. En estos casos prima el carácter eclesiástico. Junto a ellas encontramos las de Oficina de Prensa, Gabinete de Prensa, Departamento de Medios de Comunicación y Oficina Diocesana de Información. Creemos que cada denominación tiene un marcado marchamo de la época en la que se constituyó. En la utilización de la forma de nombrar eclesiástica debemos tener en cuenta la naturaleza de las funciones de estos organismos en la colaboración del gobiemo de la diócesis.

-Hay que indicar, ante todo, que la organización del régimen de gobiemo en la Iglesia diocesana, a diferencia de lo que sucede en la sociedad civil, no tiene unas normas generales fijas que definan claramente su estructura, sino que, salvo en unas pocas materias, cada obispo diocesano tiene casi una absoluta libertad en diseñar y perfilar los organismos que le pueden ayudar en su acción pastoral. Esto hace que, en realidad, sea necesario acudir a la legislación particular de cada diócesis para conocer exactamente la naturaleza técnica del organismo diocesano concreto, ya que el Código de Derecho Canónico, como decimos, nada regula sobre ello salvo unas afirmaciones muy genéricas. Podemos decir, de forma general, que "la curia episcopal" (o diocesana) se estructura en departamentos (Delegaciones, Secretariados) que asumen el estudio y tratamiento canónico y pastoral de los distintos campos de la acción ministerial del obispo... En la determinación del número y designación de los departamentos y en la asignación de las materias y de competencias se ponderarán las circunstancias de tiempo, lugar y personas, es decir, la peculiar historia y presente pastoral de la diocesis, estructurándose estos Departamentos en oficinas especializadas siempre que la importancia y complejidad del trabajo lo requieran. Actuación orgánica que se realiza en nombre del propio obispo diocesano, por lo que hay que recurrir al decreto correspondiente para conocer la potestad con que actúan, su ámbito, competencias, etc. $n$.

77 F. R. Azmar Gil, 'La delegacion o el secretarizdo de pastoral faniliar de las dibcests espatiolas', en Ciencia Tomista, $1994,387$. 
La Conferencia Episcopal Española establece en sus estatutos el carácter esencialmente pastoral de las Comisiones Episcopales, similares a las Delegaciones. Los Secretariados en este caso parecen ser organismos más técnicos. Siguiendo al prof. Federico R. Aznar, descubrimos que las diócesis españolas definen a las Delegaciones diocesanas como «departamentos de acción pastoral que, actuando directamente bajo la autoridad y dirección de los obispos, aseguran en todo el ámbito diocesano las acciones pastorales fundamentales y proveen eficazmente a las necesidades espirituales de los distintos grupos de fieles-, o como dos responsables de promover, animar y coordinar su pastoral específica-; o como arganismos que tienen el cuidado de los diferentes sectores que existen... y que actúan como órganos consultivos, técnicos y de decisión... El delegado tiene potestad delegada en aquellos asuntos que tocan a su sector ; etc. ${ }^{78}$

Respecto a los Secretariados debemos tener en cuenta las palabras de Mons. Fernando Sebastián Aguilar:

-Las Delegaciones tienen un carácter más directamente jerárquico... el delegado lo es del obispo, quien le confia la tarea de animar, promover y coordinar la acción pastoral en un área determinada dentro de la acción pastoral diocesana... Los Secretariados atienden a la animación pastoral de algunos sectores más especializados, tienen un carácter más directamente activo que las mismas Delegaciones... son organismos animadores del sector concreto encomendado... tienen un carácter más especializado y más directamente operativo que las mismas Delegaciones", indicando que das Delegaciones no son órganos de gobiemo, sino de reflexión, animación y servicio pastoral... Ni ellas ni los secretariados tienen propiamente capacidad decisoria. 79.

Como podemos observar, la doctrina, al respecto, no está clara. Aún se intenta marcar las diferencias, teniendo siempre presente esa cuasi libertad absoluta. del obispo en esta materia. Como resumen, señalar las funciones que, parece, tiene una Delegación:

-a) tener un conocimiento completo de la realidad de su área de competencia: problemas, necesidades, urgencias, perspectivas, relación con otras

78 Obispo, 'Estatudos por los que se rigen las Delegaciones diocesanas', en Boletin Oficial de Obispado de Corla-Cicenes, 115, 1999, 712-714; Obispo, 'Nueva Curia Diocesana. Para una renovada unidad de acción en la misión evangelizadora de la Iglesia paricular. Decreto', en Boletín Oficial del Obispado de Onibuela-Aticante, 240,1990, 8; Arzobispo, 'Decret sobre modificacions a l'ordenament dels organianes dibcesons', en Boletin Oficial del Arzobtopado de Tarmagona, 225, 1990, Supiemento

79 Boletin Ofictal del Obtopato de Malloga, 125, 1993, 25-31. 
áreas pastorales; $\boldsymbol{b}$ ) atender a la formación de los agentes de pastoral del propio sector, a través de los medios adecuados; c) promover y seguir el desarrollo de las acciones de un sector pastoral a todos los niveles y en todo el territorio de la diócesis; d) coordinar debidamente toda la actividad pastoral de dicho sector; $e$ ) responder a las consultas formuladas por el obispo y por otros organismos diocesanos en el área de su competencia; f) elaborar los programas de acción correspondientes al propio sector para que sean integrados en el programa pastoral diocesanos ${ }^{80}$.

La actuación apostólica en el mundo de los medios de comunicación adquiere sentido desde alguno de los flecos antes apuntados y en el marco de la disposición pastoral de cada diócesis.

\section{b) Constitución}

Respecto a las épocas en que se constituyen las Delegaciones Diocesanas de Medios de Comunicación establecemos unos ciclos de influencia histórica determinados por los acontecimientos eclesiales o las asambleas y reuniones nacionales que han servido de aliciente en esta labor apostólica.

Primer núcleo, que recoge a las Delegaciones que, en línea de continuidad, se constituyen como transformación de la Delegación Diocesana de Prensa Católica (...-1959). Algunas de ellas sufrirán un proceso de actualización en fechas posteriores y que consignaremos entre paréntesis, en las clasificaciones:

- Ávila, Barcelona, Mallorca, Santander, Tortosa.

Segundo núcleo, que abarca desde la I Reunión de Delegados Diocesanos de Prensa Católica (25-5-1959) hasta la constitución de la Conferencia Episcopal Española (febrero-marzo 1966). En esta época nacen las siguientes Delegaciones:

- Astorga, Ciudad Real, Oviedo, Salamanca.

Tercer núcleo, que comprende desde febrero-marzo de 1966 hasta la XXIX Asamblea de la Conferencia Episcopal (junio de 1978), en la que se abordó el problema de los Medios de Comunicación Social:

- Albacete, (Ávila), Canarias, (Ciudad Real), Ciudad Rodrigo, Córdoba, Cuenca, Jaén, Lugo, Lérida, Madrid, Málaga, Mondoñedo, Segorbe-Castellón, Sevilla, Urgell, Vich, Zaragoza.

80 Obispo, 'Decreto de aprobación del estatuto de las comisiones diocesanas de pastoral', en Boletin Oficial del Obispado de Codiz y Ceuta, 132, 1986, 86-90, ant 4 . 
Cuarto núcleo, desde junio de 1978 hasta el presente, con especial incidencia en la Reunión de Delegados Diocesanos de noviembre de 1992, en la que se analizó la situación de las Delegaciones de Medios de Comunicación Social:

- Alcalá, Badajoz, Barbastro, Bilbao, Burgos, Cádiz-Ceuta, CalahorraLogroño, Coria-Cáceres, Granada, Huesca, Jaca, Jerez de la Frontera, León, Orihuela-Alicante, Osma-Soria, San Sebastián, Santiago de Compostela, Sigüenza-Guadalajara, Tarazona, Teruel, Valladolid, Vitoria.

A partir de la Constitución de la Comisión Episcopal de Medios de Comunicación Social las diócesis españolas formalizan su estructura. Las fechas de constitución vienen determinadas, en la mayoría de los casos, por reuniones de carácter nacional o etapas en las que los responsables nacionales crean un clima de sensibilidad hacia estas materias. No debemos olvidar el período de la transición española que supuso la eclosión del papel de los Medios de Comunicación Social en nuestra sociedad, y que crea el necesario establecimiento de interlocutores válidos y competentes.

Otro aspecto relevante es la forma de constituirse. Encontramos decretos de erección de la Delegación Diocesana de Medios de Comunicación u organismo similar en: Bilbao, Coria-Cáceres (general para todas las Delegaciones), Mallorca, Osma-Soria.

Excepto la diócesis de Bilbao con un modélico decreto de constitución que incluye los estatutos, los decretos de constitución, en las citadas diócesis, son similares a éste:

- Una nueva Delegación Diocesana. Desde el comienzo de mi tarea episcopal en nuestra diócesis se ha sentido una desazón ante la falta de cauce concreto de nuestra Iglesia para hacernos presentes en nuestra sociedad pluriforme con un mensaje del Evangelio distinto en su presentación del que anunciamos en celebraciones, homilías, catequesis y reuniones de grupos cristianos: un mensaje en los Medios de Comunicación Social. No bastaban los loables intentos de las Hojas Parroquiales, ni siquiera el Boletín del Obispado. Tampoco la generosa oportunidad que periódicos y radios locales nos han brindado. Como todo proyecto organizativo, se necesita no sólo del impulso generoso de un momento, sino de una tarea continua que canalice cuanto sirva para difundir el Evangelio y la vida de nuestra Iglesia en los Medios de Comunicación Social.

Ésta es la razón del nacimiento de una nueva Delegación diocesana de MCS. Como toda Delegación necesita del mimo no sólo del delegado, sino de un equipo y de la ayuda imprescindible de las instituciones diocesanas, sacerdotes y laicos que vean en este campo un poderoso medio de evangelización. A ello os invito. No desaprovechemos la ocasión, ya tan tarde hemos 
puesto en marcha algo tan imporante para la vida de nuestra Iglesia como es comunicar, difundir, debatir, anunciar nuestra fe.

† Braulio, obispon ${ }^{81}$.

En algunas ocasiones la constitución de la Delegación está unida al nombramiento del delegado, casos de Badajoz y Tarazona.

La iniciativa de puesta en marcha de las Delegaciones suele estar ligada a momentos relevantes de la diócesis. En el caso de Bilbao fue la Asamblea diocesana; en el de Badajoz, el Sínodo diocesano, y en los de Calahorra-Logroño y Vitoria, la determinación explícita del Consejo Presbiteral.

En nuestra investigación hemos podido acceder a los Estatutos de las diócesis de Bilbao, Calahorra-Logroño, León y Orihuela-Alicante. Otras se conforman con un marco orientativo a modo de estatutos: Sigüenza-Guadalajara. Los estatutos analizados encontrados parecen más borradores de proyectos o planes de la Delegación que estatutos propiamente dichos. La conclusión a la que podemos llegar es el escaso aprecio por el marco juridico de este organismo, en el que se privilegia más el hacer, del día a día, que la planificación y comprensión teórico-jurídica. Un síntoma claro será la variada inclusión en la estructura diocesana.

\section{c) Estructuración diocesana}

Las Delegaciones de Medios de Comunicación Social de las diócesis españolas, en su labor pastoral, se encuentran incardinadas en el marco de las curias diocesanas, para colaborar con el Obispo en el gobierno de toda la diócesis, principalmente en la dirección de la actividad pastoral. ${ }^{82}$. Dentro de éstas dependen de los siguientes cargos:

Directamente del obispo: Osma-Soria, Santander.

De la Vicaría General: Bilbao, Burgos, Ciudad-Real, Mallorca, SigüenzaGuadalajara, Tortosa, Zamora.

De la Vicaría de Pastoral: Barbastro, Orense, Orihuela-Alicante, Tarazona, Vitoria.

De la Vicaría de Evangelización: Badajoz.

De la Vicaria de Asuntos Jurídicos, Económicos y Sociales: Coria-Cáceres.

De la Secretaría General: Ciudad-Real, Granada, Málaga, San Sebastián, Santiago de Compostela, Vich. 
De la Delegación de Enseñanza: Calahorra-Logrono.

Y se declara en la encuesta independiente: Jerez de la Frontera.

Como podemos observar no existe unanimidad a la hora de encuadrar la Delegación en una línea de coordinación pastoral. Parece claro que la tendencia es incluirla en la Vicaría General y en la Vicaria General de Pastoral. Son muy importantes las relaciones que se establecen con la Secretaría General y con la Delegación de Estadistica y Sociología, allí donde exista. Función que suele estar asumida por el secretario general. Sin duda, que la dependencia última es la del obispo. Y en el caso de esta Delegación más por la teoría de los líderes mass mediáticos y su incidencia en la opinión pública. Pretencioso parece declararse independiente. Este apartado debiera consignarse en los Estatutos. Aspecto que aparece inédito en los abordados, excepto en el de la diócesis de Bilbao.

Las Delegaciones suelen estar compuestas por un responsable, que en 38 casos es delegado; 10, director, y uno, capellán de Departamento ${ }^{83}$. En 41 casos es sacerdote diocesano; en tres, sacerdote religioso, y en ocho, laico/a. De entre éstos, 18 son graduados universitarios en Ciencias de la Información. Las Delegaciones suelen contar con un equipo de colaboradores: 18 con más de $3 ; 1$ con $3 ; 2$ con $6 ; 4$ con 1 y 23 con ninguno. La edad media de los delegados es de cincuenta y cinco años, y la de los colaboradores, de cuarenta y cinco.

\section{CONCLUSIONES}

El carácter comunicativo intrínseco del ser y del actuar de la Iglesia, comunión y misión en cada época, no exime de la obligación en la perfección humana de los medios.

Al delimitar las bases de los aspectos configuradores de la cultura institucional comunicativa de las diócesis españolas se ha descubierto un desarrollo al socaire de las necesidades concretas de las Iglesias particulares, sin un proyecto determinado y con una ausencia considerable de marco reglamentario, modelo unificador. Situación que posibilitaba y potenciaba la actuación de sacerdotes, religiosos y obispos en el ámbito comunicativo, con más buena intención y voluntad que profesionalidad. Proceso que, en estas fechas, no parece concluido.

83 Datos sacados de la Encuesa del Secretariado de la Comisión Episcopal de Medios de Comunicación Social de la Conferencia Episcopal Española, mayo 1992, 1 
Desde la escasa incidencia que la evolución de las teorias de la opinión pública ha ejercido en la reflexión de la Iglesia, aún predomina la concepción hipodérmica y lineal de los efectos de los medios de comunicación, junto con la ausencia de un interés cierto por combatir la retroalimentación desde la formación de los usuarios. Aspecto que si han recalcado algunos sínodos diocesanos, al acercarse a un diálogo inevitable con la galaxia mediática, en algunos casos verdaderamente aleccionador.

El giro copernicano del Concilio Vaticano II en nuestro país, fruto de unos años de cambio social y eclesial, originó la conciencia de la necesidad de un estrechamiento en el diálogo con la sociedad, enmancado en el modelo de anuncio y comunión. Los medios de comunicación se descubrian como instrumentos imprescindibles de formación de las conciencias en una cultura mediática y mediatizada. Surgía, de las mareas de la vida de la Iglesia, un importante proceso de opinión pública dentro de ella como fuerza reactivadora de la comunión. En este marco se encuadran las acciones proféticas de tantos hombres y mujeres de Iglesia. Cabe destacar la ralentización en el campo de la formación en la teoría y la técnica de la comunicación, más ligada, en nuestro caso, a una práctica de sacerdotes escritores en periódicos, germen de muchos de los delegados diocesanos.

La referencia constante de las diócesis ha sido la Comisión Episcopal de Medios de Comunicación de la Conferencia Episcopal Española. Y, en concreto, su Boletín. Sin este instrumento no se hubieran dado los pasos de gigante que parecen descubrir las páginas anteriores. La labor de los responsables de este organismo alimentaba un espíritu común de unidad y un potencial que, elevado a su máxima capacidad, se nos mostraba irresistible. Un factor determinante ha sido la Jornada Mundial de Medios de Comunicación Social. Los esfuerzos de permanente revitalización de este dia dedicado en la Iglesia a los medios de comunicación no parece hayan conseguido todas las metas que se pretendian. La Iglesia, con tal cantidad de reflexión, personal y medios posee una posibilidad de creación de imagen pública impresionante. La ausencia de relevancia, protagonismo en los círculos de poder y afán de movilización frena esta fuente de presencia en nuestra sociedad.

Se ha construido un camino con medios economicos y materiales escasos. Este hecho ha condicionado la actuación diaria de un ámbito en donde las nuevas tecnologias juegan un papel fundamental. No podemos olvidar que, también, la partida presupuestaria para las Delegaciones de Medios de Comunicación ha dependido del grado de sensibilidad que se tenga hacia la importancia de este organismo como medio de difusión del Evangelio. 
Hemos observado cómo no existe una nomenclatura común, a todas luces necesaria, a la hora de denominar este organismo, de nominar a su responsable y de delimitar los campos de actuación. Nos inclinamos a considerar como la forma más apropiada la de Delegación Diocesana de Medios de Comunicación Social. Asumimos aquí el aspecto técnico, referencia al concepto de Secretariado, para poner énfasis en la función pastoral. Recalcamos el aspecto jerárquico desde una perspectiva más globalizadora de la actuación apostólica. Incluimos el aspecto técnico en un marco más amplio de contextualización, nueva tendencia de la comunicación global. Misión que incluirá dos aspectos: hacia dentro, comunicación interna-servicio pastoral, y hacia fuera, comunicación externa-gabinete de prensa y relaciones públicas.

La comunicación interna es el ámbito de interacciones entre los miembros de la Iglesia. Definimos los destinatarios y sujetos desde el staff jerárquico: obispo/s, vicarios, arziprestes, delegados... En otro nivel, los sacerdotes, religiosos/as, miembros de institutos seculares y prelaturas personales y de sociedades de vida apostólica y los cristianos laicos, con la diferencia entre los que participan de forma activa en movimientos de apostolado seglar y los cristianos que se relacionan con las comunidades parroquiales, sin más compromiso específico que su confesión de fe. La Delegación debe canalizar los flujos de entrada de información: información general y la propia teológico-eclesiástica. Debe mantener un centro de documentación multimedia, con material debidamente clasificado, catalogado y de acceso fácil, adecuado a las necesidades de los potenciales usuarios. Debe saber encontrar la información, conexión con las fuentes primarias, secundarias, y con los medios, valorarla y transmitirla.

Destacamos la necesidad de un dossier de prensa o Boletín de la delegación para uso interno de la curia diocesana, de periodicidad diaria, espejo de lo que acontece en el mundo y que tenga incidencia en la misión de la Iglesia. De tirada restringida, monográfico en ocasiones. Debe adquirir el carácter de confidencial, de fuentes múltiples. Este ejercicio supondria un medio para el análisis de la realidad y su valoración. Otra tarea puede ser el asesoramiento y coondinación de actividades publicísticas de otras delegaciones, relación necesaria a la hora de catapultar información al exterior. Debe contar la Delegación con una base de datos amplia de agentes de la comunicación y de expertos en materias tanto civiles como eclesiásticas. De entre ellos, no estaria de más formar un consejo editor para que determinara las lineas generales o analizara procesos comunicativos de especial complejidad.

Un elemento necesario es el togotipo de la Delegación junto con todos aquellos instrumentos de imagen de marca, inmersos en un diseño ajeno a la estética clerical. 
No debe ser ajena a la Delegación la participación en la preparación de grandes celebraciones diocesanas para fundamentar la conciencia colectiva con las técnicas de la psicología social.

Con especial cuidado debe analizar y tratar los estados de opinión pública interna, de opinión eclesial. Coordinar actividades informativas de órganos inferiores, alejada de toda actuación de injerencia. Ofrecimiento y flujo de información y creación de una pequeña red de corresponsales en parroquias y movimientos.

Una labor formativa requiere un cuidado especial. Formación en los distintos niveles: sacerdotes, seminaristas, movimientos apostólicos, parroquias... Debiera regirse por un programa de acciones que abarcara diversos aspectos y, sobre todo, el uso crítico de los medios de comunicación. Debe buscar fórmulas de ayuda a la investigación en el campo de las ciencias de la comunicación.

Introducimos la comunicación intermedia, relaciones con otras organizaciones e instituciones, en la comunicación externa para simplificar los procesos. La comunicación externa se refiere a la comunicación con la sociedad. El centro de atención son los medios de comunicación de masas que juegan el papel de protagonistas como intermediarios. La transparencia informativa debe ser la linea dominante de actuación. Hacemos especial hincapié en la función de una publicación diocesana, a mitad de camino entre la comunicación interna y la externa. Una publicación que sea vínculo de comunión por la información, la formación y el entretenimiento, y que sirva para presentar la Iglesia a la sociedad. La Delegación debe asumir el carácter empresarial de la forma más conveniente en cada momento. En la práctica, la periodicidad, número de páginas, secciones, equipo redaccional y técnico vendrán determinadas por las circunstancias. Es necesario un plan de marketing como base de cualquier iniciativa.

En la comunicación externa nos encontramos frente a la sociedad, a los hombres y las mujeres de buena voluntad. La base es la diocesis como generadora de noticias. Se deben determinar las estrategias en cada caso: intervenciones del portavoz, comunicados y notas de prensa, ruedas de prensa, conferencias de prensa, elaboración de -dossiers" externos, argumentarios, materiales informativos, notas de rectificación... Un apartado importante es el trabajo sobre los documentos tanto de la Santa Sede, de la Conferencia Episcopal como del obispo o de los diversos organismos diocesanos. Todo el material debiera ser redactado en técnica periodistica y adaptado al medio y al nivel de audiencia. Relevante es la labor de facilitar el trabajo a los medios en asuntos referidos a la Iglesia local: concertación de encuentros, entrevistas, visitas a parroquias, instituciones de Iglesia, encuentros informales con periodistas, directores... Es conveniente servir de 
agencia de opinión, no sólo de información. En este marco, la función del portavoz adquiere un nuevo sentido. Creemos que el portavoz debe ser el delegado diocesano de Medios de Comunicación Social, para así mejor integrar sus actuaciones públicas en una estrategia conjunta.

La llamada familiaridad electrónica acentúa la personalización de la información. Las noticias con rostro se hacen protagonistas principales de los argumentos informativos en los medios. La Iglesia no escapa a esta marea. Las informaciones referidas al obispo cobran singular fuerza, por el contagio de esquemas en relación con otros líderes sociales y políticos. Se ha configurado el estatus de los líderes massmediáticos ${ }^{84}$. Aspecto tratado por Pierre Babin cuando habla de la paradoja del comunicador cristiano, paradoja de fuerza y debilidad ${ }^{85}$.

Un sintoma del carácter espontáneo de estos organismos es la inexistencia de una cultura de formalidad jurídica a la hora de constituirse. La práctica inexistencia, salvo honrosas excepciones, de decretos de constitución y de estatutos de actuación nos indican la necesidad de estos medios jurídicos para el buen funcionamiento de las Delegaciones. Quizá, en estos tiempos de cierta consolidación, no estaría de más que se elaboraran los estatutos de las Delegaciones. Estatutos que deben comprender: una pequeña parte introductoria del marco doctrinal de la actividad pastoral de la Iglesia universal y de la diocesana en los medios de comunicación, la fórmula jurídica de la constitución de los estatutos y las normas con la definición del organismo en la curia, las funciones, las personas y sus denominaciones, la estructura del organismo, las cuestiones relativas al presupuesto y a los medios y la vigencia del estatuto.

Creemos que la Delegación Diocesana de Medios de Comunicación Social debe depender de la Vicaría General con competencias en el campo pastoral $\mathrm{u}$ organismo similar. Mantendrá especial relación con la Secretaría General y con la administración diocesana. Y dado el incremento de los efectos de la persona y actuaciones del obispo como líder massmediático, debe estar en estrecha relación con el prelado.

La unidad terminológica en la denominación de los organismos en los que se constituye la Delegación, servicio pastoral y gabinete de Prensa y relaciones públicas, debe incluir a las personas. Proponemos como más adecuado a la realidad el término de delegado/a diocesano de Medios de Comunicación Social. En aquellas diócesis de gran actividad y con personal

84 Cf. A. Muñoz Alonso et alii, Opinión príblica y comunicación politica, Madrid 1992, 354-380.

85 P. Babin, La era de la comunicación. Para un nuevo modo de exangelizar, Santander 1990 , 100 y ss. 
capacitado para cada ámbito de actuación, se pueden nombrar un director del gabinete de Prensa y relaciones públicas y un coordinador del servicio pastoral; este último cargo ligado, en la mayoría de los casos, a la persona del delegado, aún en estas circunstancias. No debemos olvidar la importancia de la profesionalidad y la técnica en este campo, factores que facilitan la integración de laicos, formados teológicamente en esta Delegación. La dedicación debe ser plena para los responsables, con una remuneración digna, a tenor del Código de Derecho Canónico en su canon 231.

Toda delegación debiera elaborar un Plan de Pastoral de Comunicaciones según las pautas de la Instrucción pastoral Aetatis Novae. Las últimas reuniones de delegados diocesanos se han preocupado de este aspecto. El Plan de Pastoral de Comunicaciones debe ser un instrumento más en el Plan de Pastoral de la Diócesis, no un programa de actuación independiente.

José Francisco Serrano Oceja Universidad Pontificia de Salamanca 